\title{
LA FORMA DE GOBIERNO EN EL DEBATE CONSTITUYENTE DE 1869
}

HORTENSIA GONZÁLEZ RODRÍGUEZ

Universidad San Pablo-CEU 


\section{SUMARIO}

I. Introducción. II. La Monarouía como forma de gobierno. Monarouia y DEMOCRACIA. III. LA FORMA DE GOBIERNO MONÁROUICA EN LOS MODELOS POLITICOS COMPARADOS Y LA REVOLUCIÓN DE 1869. IV. EL PLEBISCITO SOBRE LA CUEStIÓN DE LA FORMA dE GOBIERNO. V. LA MONARQUía deMOCRÁtICA. VI. LA RePÚBLICA FEDERAL VERSUS REPÚBLICA UNITARIA. 


\title{
LA FORMA DE GOBIERNO EN EL DEBATE CONSTITUYENTE DE 1869
}

\author{
POR \\ HORTENSIA GONZÁLEZ RODRÍGUEZ \\ Universidad San Pablo-CEU
}

\section{INTRODUCCIÓN}

Por primera vez en la historia constitucional española se va a introducir en el debate constituyente de 1869 la cuestión de la forma de gobierno. Ciertamente, ya en 1854 se habían oído voces críticas contra la Reina Isabel II, incluso contra la dinastía y la propia institución monárquica, pero, no será hasta 1869 cuando el debate MonarquíaRepública se plantee en toda su plenitud.

El asunto de la forma de gobierno ya habia sido tratado en las Cortes Constituyentes de 1869 con motivo de la discusión del voto de gracias al Gobierno Provisional el 22 de febrero, antes de iniciarse el debate constituyente ${ }^{1}$. La discusión parlamentaria de los artículos 32 y 33 del proyecto constitucional, daría lugar a una de las más brillantes discusiones doctrinales nunca habidas hasta entonces en la tribuna española, no sólo por la forma externa de las alocuciones parlamentarias sino también por la profundidad de los alegatos empleados por sus oradores ${ }^{2}$. El artículo 32 del proyecto constitucional de 1869

1 Son muchas las referencias a la forma de gobierno antes del debate constitucional, ya el 24 de febrero Castelar habia planteado el dilema Monarquía-República. DSCC 12, pág. 198.

2 De torneo oratorio y palestra de elocuencia se han calificado a los debates del proyecto constitucional que se iniciaría el 6 de abril de 1869. Fundamental a este tema es la obra de Cañamaque, "Los oradores de 1869", quien afirma que en este terreno las Cortes de 1869 son las mejores del mundo. 
va a residenciar de manera esencial la soberanía en la Nación, "de la cual emanan todos los poderes", y definirá en su artículo 33 a la Monarquía de una manera absolutamente novedosa en nuestro Derecho Constitucional como "la forma de gobierno de la Nación española», trasladando al Título IV el desarrollo de las competencias del Rey. Como las enmiendas que la minoría había presentado al artículo 32 del proyecto constitucional que proclamaba la soberanía nacional, implicaban la discusión del artículo siguiente, fue el Diputado Olózaga, Presidente de la Comisión Constitucional, primero, y la Cámara después, quienes decidieron que por la íntima conexión entre ambos preceptos se debatiesen de forma conjunta, existiendo seis turnos a favor $y$ seis en contra. Las enmiendas referidas habian sido presentadas por la minoría republicana con objeto de ampliar el debate y eran, en expresión de Silvela, una especie de guerrillas que desplegaba la minoría antes de dar la batalla ${ }^{3}$.

La discusión parlamentaria de los articulos 32 y 33 del proyecto constitucional tuvo una duración de ocho dias, del 12 al 20 de mayo de 1869. En el debate parlamentario se pueden distinguir dos partes claramente diferenciadas: una primera, en la que se va a defender la República a través de las numerosas enmiendas presentadas a los citados artículos del proyecto constitucional, y una segunda, en la que se atacará de manera frontal a la propia institución monárquica. De esta manera, la discusión doctrinal sobre la forma de gobierno se va a centrar fundamentalmente en la alternativa Monarquía democrática o República (federal o unitaria), quedando al margen de esta discusión la llamada Monarquía doctrinaria defendida por don Antonio Cánovas del Castillo en su discurso del 12 de abril sobre el "poder armónico", la cual, indirectamente orientaba a la restauración borbónica; y la Monarquía tradicionalista de don Carlos, al ausentarse de este debate la minoría carlista que había abandonado el hemiciclo después de la aprobación del artículo 21 que reconocía la libertad de cultos.

La Constitución democrática de 1869 iba a establecer una Monarquía con facultades y prerrogativas muy parecidas sobre el papel a las que ya habian reconocido anteriores textos constitucionales, como la disolución, la convocatoria, suspensión y cierre de las sesiones parlamentarias (art. 42); la iniciativa legislativa (art. 54); la sanción y promulgación de las leyes (art. 34); el libre nombramiento y separación de los ministros (art. 68); etc. Sin embargo, la Monarquía que iba a 
nacer de la Revolución de Septiembre estaba impregnada de los principios del liberalismo radical que habían inspirado ésta dotándola de un significado nuevo y diferente al de la anterior Monarquía derribada. El reconocimiento de la soberanía nacional vinculada al sufragio universal, la existencia de una amplia, explícita y cuidada declaración de derechos absolutos e ilegislables y una estricta delimitación de los poderes del monarca configuran el carácter de la nueva Monarquía, $y$ es que, como ha dicho Carr, el artículo 33 era el término medio entre el deseo de los unionistas de "una Monarquía con todos sus atributos", y la democracia "con todas sus consecuencias" de los progresistas $y$ sus aliados los demócratas cimbrios 4 . Si bien es cierto, como dice Sánchez Agesta ${ }^{5}$, que entre ambos tipos de Monarquías hay coincidencias iniciales: la Monarquía es el principio de continuidad encarnado en la herencia; la Monarquía es la imparcialidad y neutralidad de un poder supremo en la lucha de los partidos; la Monarquía es incluso un principio de autoridad que puede refrenar el abuso de autoridad; la Monarquía es también representación nacional y una jerarquía social; la diferencia esencial habría que referirla a la relación entre la soberanía y la Monarquía. De esta manera, frente a la Monarquía doctrinaria del período anterior que aceptaba la existencia de dos poderes históricos, Monarquía y representación nacional, que compartían la soberanía; la Monarquía democrática nacida de la Revolución se va a fundar exclusivamente en la soberanía nacional, quedando configurada como un poder constituido que la Nación establecía y podía revocar.

La Monarquía como forma de gobierno será defendida ${ }^{6}$ en 1869 por las fuerzas políticas que habian coadyuvado al triunfo de la Revolución Septembrina, y que formaban parte de esa gran coalición revolucionaria que había triunfado en las elecciones a Cortes Constituyentes de enero de 1869, coalición formada por progresistas, unio-

4 CARR, R., España 1808-1975, Ariel Historia, Barcelona, 1998, pág. 307.

5 SÁNCHez Agesta, L.: Historia del Constitucionalismo español (1808-1936), CEC, Madrid, 1984, pág. 285.

6 Las exposiciones a favor de la Monarquía serían las siguientes: el discurso de don Segismundo Moret en la sesión del 8 de abril de 1869; don Antonio de los Ríos Rosas el día 9 de abril; don Augusto Ulloa y Castallón en un memorable discurso del 13 de mayo de 1869 en contestación a otro del Marqués de Albaida de cuatro horas de duración; el Duque de Mandas, don Fermín Lasala, en la sesión del 14 de mayo; don Manuel Silvela en su discurso del 17 de mayo; don Eugenio Montero Ríos y don Gabriel Rodríguez el 18 de mayo; don Cirilo Álvarez el 19 de mayo; y finalmente don Vicente Romero Girón y don Antonio de los Ríos Rosas en un choque de gran altura con el tribuno Castelar en la sesión del 20 de mayo. 
nistas, y cimbrios, quienes además iban a integrar exclusivamente la Comisión Constitucional encargada de elaborar el texto constitucional7. De esta manera, la Comisión Constitucional llevaba a la práctica los postulados contenidos en el manifiesto a la Nación del Gobierno Provisional de 25 de octubre de 1868 en el que se iban a declarar como objetivos de la Revolución: el establecimiento del sufragio universal, "como la demostración evidente y más palpable de la soberanía del pueblo"; la libertad de cultos, de enseñanza, de imprenta, de reunión y de asociación ureconocidas como dogmas fundamentales por la Revolución española»; y la Monarquía constitucional. El Gobierno Provisional, como dice Jutglar ${ }^{8}$, faltando a las normas de la más elemental neutralidad, hizo gala de sus preferencias monárquicas en el Decreto de 6 de diciembre al mostrar sus esperanzas "en que salgan victoriosos de las urnas los mantenedores de ese principio y de un monarca, no electivo, sino elegido por aquellos a quienes el pueblo español otorgue al efecto sus poderesn. Previamente, el 12 de noviembre de 1868 se había formulado un programa de conciliación, aceptado por personalidades tan diversas como los unionistas Ríos Rosas y Silvela, los progresistas Olózaga y Madoz, o los demócratas Rivero, Becerra y Martos, en el que se habían sentado las siguientes bases: soberanía de la Nación y sufragio universal, seguridad individual, inviolabilidad del domicilio y la correspondencia, derecho de reunión

7 En la sesión del 2 de marzo se presentaba una proposición para el nombramiento de la Comisión Constitucional compuesta de 15 miembros. Finalmente serían elegidos cinco unionistas (Rios Rosas, Diputado por Ronda con 179 votos; Posada Herrera, Diputado por Lorca con 177 votos; Silvela, Diputado por Ávila con 176 votos; el Marqués de la Vega de Armijo, Diputado por Córdoba con 178 votos; y Augusto Ulloa, Diputado por Mondoñedo con 176 votos), cinco progresistas (Salustiano Olózaga, Diputado por Logroño con 181 votos; Aguirre, Diputado por Soria con 179 votos; Cristóbal Valera, Diputado por Albacete con 178 votos; Mata, Diputado por Tarragona con 179 votos; y Montero Ríos, Diputado por Pontevedra con 178 votos), y cinco demócratas (Martos, Diputado por Ocaña con 177 votos; Moret, Diputado por Ciudad Real con 176 votos; Becerra, Diputado por Madrid con 175 votos; Godínez de la Paz, Diputado por Plasencia con 174 votos; y Romero Girón, Diputado por Cuenca con 174 votos). Presidiría la Comisión Olózaga, siendo secretarios Romero Girón y Moret.

Las Cortes discutieron el proyecto constitucional en el corto espacio de tiempo que media entre el 6 de abril y el 26 de mayo de 1869. Una vez la Comisión Constitucional revisó las modificaciones introducidas pasaría a la Comisión de corrección de estilo, de donde saldría para finalmente ser votada el 1 de junio de 1869, siendo aprobada por 214 votos a favor y 55 en contra.

8 Jutglar, «Revolución de Septiembre, El Gobierno Provisional y el reinado de Amadeo", en Historia de España de MenénDez PIDAL, t. XXXIV, pág. 653. 
y de asociación pacíficas, libertad de prensa y enseñanza, libertad religiosa, unidad de legislación y de fueros, la institución del jurado $y$ Monarquía constitucional. Por este motivo un importante sector del Partido Demócrata, liderado por el Marqués de Albaida, se separa. Los partidarios de la Monarquía serán conocidos con el nombre de "cimbrios" por declaración contenida en el manifiesto de 12 de noviembre según la cual decían haber «marchado a la pelea, abrazados a los principios populares como aquellos antiguos cimbrios que combatían encadenados para mejor defender sus mujeres, sus hijos y su hacienda", y apoyarán coyunturalmente la forma de gobierno monárquica por ser «la forma que imponen con irresistible fuerza la consolidación de la libertad y las exigencias de la Revolución».

De otra parte, el sector republicano del Partido Demócrata se organizaba paralelamente después del mitin del Circo Price el 13 de noviembre del que saldrá el Comité Republicano de Madrid formado entre otros por Orense, Castelar, Pierrad, y Pi y Margall, elaborando un manifiesto redactado por el gran orador Castelar en el que se dirá que «la República es la forma esencial de la democracia, como el cuerpo humano es la forma esencial de nuestra vida (...). La Monarquía es una institución de tal manera injusta y absurda, que donde existe sólo existe para conservar algún privilegio, para sostener alguna iniquidad"9. La escisión de los demócratas se hará definitiva cuando se publica el 17 de noviembre un manifiesto en el sector encabezado por José María Orense en el que se declaran inequívocamente republicanos y se afirma que «al igual en América que en Europa, sólo existe la democracia donde existe la República» ${ }^{10}$. Para Eiras Roel, los demó-

9 Dice Fernández Almagro que monárquicos y republicanos hicieron alarde de sus respectivas fuerzas en días muy próximos, recorriendo en manifestación - los primeros, el 15 de noviembre; los segundos el 22 siguiente - las calles céntricas de Madrid, pero en sentido inverso. Los monárquicos desfilaron desde la explanada de las Caballerizas hasta el paseo del Pardo, y Serrano, Prim y Olózaga les dirigieron la palabra desde los balcones de la Presidencia del Consejo de Ministros. Los republicanos tuvieron por tribuno a Castelar, ante el Obelisco del 2 de mayo, y marcharon por la calle Alcalá a la plaza de la Armeria, disolviéndose entre los vitores y los "muera" a que parecían excitarles la pétrea majestad del Palacio de Oriente. Fernández Almagro, M., op. cit., págs. 30-31.

10 Conviene no olvidar, que de tal trascendencia fue la cuestión de la forma de gobierno, que fueron las diferencias sobre éste y no otro asunto, el que provocó la escisión del Partido Demócrata en republicanos y cimbrios, tras el mitin celebrado por los demócratas el 11 de octubre de 1868 en el Circo Price, presidida por don José María Orense, Marqués de Albaida, en la que se acordó por sorpresa y aclamación que la República federal era la forma de gobierno que adop- 
cratas habían sido el cerebro de la Revolución que le proporcionó el impulso ideológico, lo que explicaría el deslizamiento hacia una revolución social de un pronunciamiento que fue encabezado por liberales de la Monarquía de Isabel II11.

Los comicios celebrados los días 15 y 18 de enero de 1869 darían el triunfo a al coalición monárquico democrática. Los cimbrios formando parte de esta gran coalición obtuvieron más de 20 actas de diputados en Madrid, Extremadura, y algunas provincias como Galicia, Castilla y Valencia, siendo elegidos parlamentarios Federico Balart, Manuel Becerra, Tomás Carretero, Rafael Coronel, José Echegaray, Ruperto Fernández de las Cuevas, Carlos Godínez de Paz, Pedro González Marrón, José Jimeno, Antonio López Botas, Federico Macias, Ricardo Martínez, Cristino Martos, Manuel Merelo, Luis de Moliní, Segismundo Moret, Juan Pardela, Pedro Pastor, Juan Manuel Pereira, Nicolás María Rivero, Gabriel Rodríguez, Vicente Romero Girón, Jerónimo Sánchez Borguella y Miguel Uzuriaga.

En el lado opuesto, la minoría republicana con una composición ideológica muy diversa. La minoría republicana había obtenido en las elecciones de 1869 unos resultados muy favorables al obtener más de 80 actas de los 402 escaños en litigio ${ }^{12}$. Habían obtenido nada menos

taba la democracia española. Los demócratas que no se sintieron atraídos por el federalismo del Marqués de Albaida se pronunciaron a favor de la Monarquia el 12 de noviembre de ese año en un manifiesto de conciliación firmado entre otros por don Cristino Martos, don Nicolás María Rivero, o don Manuel Becerra entre otros, partidarios de la accidentalidad de las formas de gobierno. Para estos, esta Monarquía es "la que nace del derecho de los pueblos, la que consagra el sufragio universal, la que simboliza la soberanía de la Nación, la que consolida y lleva consigo todas las libertades públicas; la que personifica, en fin, los derechos de ciudadano, superiores a todas las instituciones y a todos los poderes. Es la Monarquía que destruye, radicalmente, el derecho divino y la supremacía de una familia sobre la Nación; la Monarquía rodeada de instituciones democráticas, la Monarquía popular».

11 EIRAS Roel, A.: El Partido Demócrata español (1949-1868), Madrid, 1961, págs. 407-409.

12 No hay cifras exactas sobre el número de diputados que correspondía a las distintas fuerzas politicas. Según estimaciones los progresistas alcanzaron un número entre 130 y 160 escaños, los unionistas entre 80 y 90 , los republicanos entre 70 y 85 y demócratas-monárquicos entre 40 y 45 ; la minoría carlistas se estima que obtuvo entre 16 y 20 escaños. Martínez Cuadrado, La elección general para las Cortes Constituyentes de 1869. Revista de Estudios Políticos, 132, 1967, pág. 65-93. Por su parte Carro Martínez destaca los siguientes grupos dentro de las Constituyentes de 1869: el grupo carlista con 18 escaños entre los que desataca el Cardenal Arzobispo de Santiago, el Obispo de Jaén, Vinader, Ochoa, y el canónigo Mante- 
que todas las actas de la provincia de Lérida; todas menos una en las provincias de Sevilla, Cádiz y Huesca; importantes mayorías en Barcelona donde consiguieron 13 escaños, en Gerona y Zaragoza con 5 escaños respectivamente; además de minorias muy representativas en Valencia donde alcanzaron los 6 escaños, Málaga con 5, en Alicante, Badajoz y Tarragona donde lograron 3 escaños en cada una de estas provincias, en Murcia y Palencia con 2 escaños respectivamente; también consiguieron un diputado en Almería, Granada, Guadalajara, Salamanca, León, Teruel, Toledo y Valladolid ${ }^{13}$. El partido

rola; el grupo isabelino con un número de 14 diputados presididos por Cánovias; los unionistas con 69 escaños dirigidos por Ríos Rosas; los progresistas con Prim, Olózaga, Sagasta y Ruiz Zorrilla a la cabeza de un total de 156 diputados; el grupo demócrata con 20 diputados dirigidos por Rivero y Martos; y finalmente el grupo republicano con 69 diputados entre los que destacaban Orense, Figueras y Castelar. Carro Martínez, La Constitución española de 1869, pág. 114. Para Henessy, el partido progresista obtuvo 159 diputados, el demócrata 20, el unionista 69, el republicano federal también 69 , el republicano unitario 2, el partido carlista 18 y finalmente los isabelinos obtendrian 14 diputados. Ubieto, Reglá, Jover y Seco, Introducción a la Historia de España, "La Gloriosa" y su frustración (1868-1874), pág. 644. Para Jutglar, los federales consiguieron 80 escaños, 2 los republicanos unitarios, más de 30 los carlistas, 160 escaños los progresistas, 80 más o menos los unionistas y casi 40 los cimbrios demócratas, además del grupo monárquico partidario de Alfonso XII y capitaneado por Cánovas. Jutglar, Historia de España de Menéndez Pidal, tomo XXXIV, pág. 654. Santiago Petschen adjudica a los progresistas 126 diputados, 83 a la Unión liberal, 63 a los republicanos, 21 a los demócratas, 20 a los tradicionalistas, y 3 a los representantes del clero. "Iglesia-Estado: un cambio político. Las constituyentes de 1869", Madrid, 1975.

${ }_{13} Y$ todo ello a pesar de que el sistema electoral mayoritario simple les habia privado de la posibilidad de obtener escaño en muchos de los distritos del Norte y en Madrid, donde por ejemplo obtuvieron 109.249 votos frente a los 233.192 de la coalición de los monárquicos. En las Constituyentes de 1869 obtendrian actas de diputado, Agustín Albors por la provincia de Alicante; Miguel Alcantú por la Badajoz; Eduardo Benot, Ramón de Cala y Fermín Salvochea por la de Cádiz; Juan Pablo Soler y Joaquín Gil Berges en Aragón; Juan Tutau en el Ampurdán; Eduardo Palanca por Málaga; José Cristóbal Sorní por Valencia; y personajes atípicos como Pablo Alsina cooperativista catalán de cual se ha dicho que fue el primer diputado obrero de nuestra historia. Junto a estos se encontrarian nuevas y viejas glorias del grupo demócrata como José María Orense, Marqués de Albaida, Fernando Garrido, Miguel Ferrer; $y$ las grandes figuras de la I República española como Emilio Castelar y Ripoll, Francisco Pi y Margall, y Estanislao Figueras y Moragas. Junto a ellos, pero defendiendo un proyecto republicano completamente diferente al modelo federal, se encontraban los republicanos unitarios con Eugenio García Ruiz, quien destacaría también en las Constituyentes de 1869 por su tendencia anticlerical, y Julián Sánchez Ruano los cuales habian obtenidos sus escaños en los distritos de Palencia y Castuera (Badajoz). 
republicano no había hecho sino consolidar los resultados obtenidos en las elecciones municipales de diciembre de 1868 donde habian conquistado las alcaldías de Lérida, Barcelona, Tarragona, Zaragoza, Huesca, Teruel, Valencia, Alicante, Murcia, Córdoba, Cádiz, Huelva, Jaén, Málaga, Sevilla, La Coruña, Orense, Santander, Toledo y Valladolid. La constatación de estos resultados llevaría al Marqués de Albaida a manifestar que sólo en los pequeños pueblos y aldeas donde hundía sus raíces el caciquismo puesto en marcha desde el Ministerio de la Gobernación se había votado en sentido monárquico, y aun en ciertas provincias de tradición monárquica como Valladolid y Santander, y en las ciudades se había votado a favor de la República, por lo que a juicio de éste, el voto urbano, el voto "limpio" era republicano, y el Rey que se trajera no se le podría llamar el Rey de las ciudades sino que con mucha razón sería el «Rey de las selvas", porque las ciudades, es decir, la parte más inteligente e importante de la Nación, no le habian votado ${ }^{14}$. Y en el mismo sentido se pronunciaba el federalista Sorní, para quien, si se comparaba el número de diputados monárquicos con el de republicanos no se podía sostener que la mayoría del país fuera republicana, sin embargo, si se examinaba la importancia de las poblaciones que habian elegido a los candidatos republicanos, se demostraría que el país en su parte más consciente, más inteligente era republicana. Ese era el caso de Cataluña, Andalucía, Aragón, Valencia..., e incluso en las circunscripciones en las que no habían vencido, en las poblaciones importantes como Santander, El Ferrol o Játiva viendo las actas electorales, se ponia de manifiesto que en las grandes poblaciones había triunfado el partido republicano y sólo habia sido neutralizado por el voto de los pueblos rurales. Es decir, para los republicanos "los candidatos monárquicos habian triunfado por los votos que habían obtenido en las poblaciones más ignorantes, mientras que las poblaciones más inteligentes, más ilustradas, las poblaciones que habían votado con conciencia de lo que se votaban, la mayoría había sido republicana» ${ }^{15}$. Como ocurriría en las elecciones municipales del 12 de abril de 1931, los concejales monárquicos ganarian gracias al voto rural en contraste con el claro triunfo republicano en las capitales de provincia y principales ciudades del país, sin embargo, en 1869, a diferencia de lo que sucedería en 1931, no significó el fin de la Monarquía.

14 Orense, DSCC III, 72, 12 de mayo, pág. 1893.

15 Sorni, DSCC IV, 76, 18 de mayo, pág. 2034. 


\section{LA MONARQUÍA COMO FORMA DE GOBIERNO. MONARQUÍA Y DEMOCRACIA}

En 1869 se promulgaría la primera Constitución monárquicodemocrática de la historia constitucional española. Ahora bien, como señala Calero' ${ }^{16}$, apenas ha habido una teoría coherente y sistemática de la Monarquía democrática en nuestra historia constitucional, al contrario de lo que ha ocurrido con la Monarquía doctrinaria. Así, para encontrar una teoría de la Monarquía democrática es preciso acudir a las discusiones de las Cortes Constituyentes en que los partidos republicanos presentaron una alternativa al "régimen secular», $y$ las fuerzas que controlaban el proceso político ofrecieron y teorizaron una Constitución monárquico-democrática. Así ocurrió de forma embrionaria y casi tangencial en las Cortes de 1854-56, y de manera frontal y plena en las de 1869. Pudiendo decirse que en estas últimas Cortes se diseñó una teoría de la Monarquía democrática como respuesta a las acusaciones de la minoría republicana.

El artículo 33 no tiene precedentes en nuestro Derecho Constitucional histórico. Por primera vez en nuestra historia constitucional se iba a configurar a la Monarquía como forma de gobierno, y no como forma de Estado, abriéndose, de esta manera y sin ambigüedades, pleno paso al principio democrático frente al principio monárquico ${ }^{17}$. El reconocimiento de la soberanía nacional proclamado en algunas Cons-

16 Calero, A. M.': Monarquía y Democracia en las Cortes de 1869, Madrid, 1987, pág. XII.

17 Así, F. J STAHL, el teorizador de la Monarquía constitucional prusiana, en su libro Revolución y Monarquía Constitucional distinguía entre Monarquía como forma de Estado y Monarquía como forma de gobierno. Cuando la soberanía dejaba de residir en el monarca para residir en el pueblo, la Monarquía dejaba de ser forma de Estado para convertirse en forma de gobierno. Entendía como línea fundamental del principio monárquico el rechazo de la soberanía popular y el reconocimiento de la soberanía del príncipe. También el rechazo de la Monarquía parlamentaria. Die Revolution und die konstitutionelle Monarchie, $2 .^{a}$ ed., 1849. En el mismo sentido, Jellinek afirmará que «en la historia de Inglaterra aparecen, pues, sucesivamente, las tres Monarquias limitadas de la Edad Media y de los tiempos modernos: la de estados o clases, la constitucional y la parlamentaria. De ellas, la primera y la segunda son susceptibles de una concepción netamente jurídica, en tanto que la tercera forma una especie política de Monarquía que descansa sobre las relaciones concretas de poder de los dos órganos inmediatos del Estado; esto es, se trata de una manera de ejercer el gobierno, pero no es una forma de Estado estrictamente jurídica". JELLINEK, Teoría general del Estado, Madrid, 1981, pág. 531. 
tituciones europeas como la Constitución francesa de 1830, o la belga de 1831, o incluso el Estatuto Albertino de 1848, no habia significado un desplazamiento efectivo del poder real, de tal forma que el monarca continuaba siendo titular del poder constituyente a través de la ficción del pacto entre el monarca y la representación popular, corriente doctrinaria que también recibirá la Constitución española de 1845 por influencia del doctrinarismo francés, y que desarrollará en toda su plenitud la Constitución canovista de 1876 con la teoría de la "Constitución internan. En el texto de 1869 se va a producir una afirmación inequívoca del principio democrático desde el momento en que su artículo 32 proclama como único titular de la soberanía a la Nación, al señalar que "la soberanía reside esencialmente en la Nación, de la cual emanan todos los poderes". Pero, además, el reconocimiento de la soberanía nacional no va a suponer la exclusión en el proceso de formación de la voluntad política de las clases sociales menos favorecidas a través del recurso al sufragio censitario o capacitario, sino que la soberanía se va a encontrar estrechamente vinculada al reconocimiento del sufragio universal. $Y$ es que desde los primeros momentos de "La Gloriosa", el sufragio universal va a ser proclamado por las juntas revolucionarias como uno de los objetivos principales de la Revolución de Septiembre. El mismo Gobierno Provisional así lo proclamaba en el manifiesto que dirige a la Nación el 25 de octubre cuando afirma que "la Revolución ha establecido el sufragio universal como la demostración más evidente y palpable de la soberanía del pueblo". Como no podía ser de otra manera, las elecciones a Cortes Constituyentes se harán de acuerdo al Decreto sobre el ejercicio del sufragio universal de 9 de noviembre de 1869. Los constituyentes de 1869 introducirán el sufragio universal dentro del título I, que consagra los derechos naturales, absolutos e ilegislables de los españoles, prescribiendo el artículo 16 del texto constitucional que uningún español que se halle en el pleno goce de sus derechos civiles podrá ser privado de su derecho a votar en las elecciones de senadores, diputados a Cortes, diputados provinciales y concejales". A diferencia de la anterior etapa constitucional en que la Monarquía estaba siendo ya forma de gobierno sin dejar de ser todavía forma de Estado, por cuanto la soberanía continuaba residiendo en el monarca, aunque fuese de manera compartida, en 1869 sólo se puede hablar de la Monarquía únicamente como forma de gobierno, y ello es asi, porque en el texto de 1869 se producirá un auténtico desplazamiento del principio monárquico que dejará de tener trascendencia jurídica.

Siguiendo con esta argumentación, podemos señalar que la principal crítica de la minoría republicana en las Constituyentes de 1869 a 
la forma de gobierno monárquica será su incompatibilidad con el principio democrático ${ }^{18}$, como dijera Castelar, poner la Monarquía junto a la democracia era como poner un pedazo de hielo en el fuego, y así, o el fuego derretía al hielo, o el hielo apagaba el fuego ${ }^{19}$. Para los republicanos no había accidentalidad posible de las formas de gobierno. La forma era inseparable de la esencia y adecuada a su naturaleza. Así, combinar la democracia con la Monarquía familiar o dinástica que representaba el principio de perpetuidad de los poderes, de su vinculación en una familia y de su transmisión por medio de la herencia, no era ni Monarquía ni democracia, era como tener «una Monarquía impotente y una democracia infecunda» ${ }^{20}$.

Monarquía y democracia eran incompatibles a juicio de estos, porque la soberanía del pueblo era incompatible con la existencia de un poder irresponsable, inviolable y hereditario, porque "donde hay Monarquia hereditaria la soberania del pueblo es poco menos que ilusoria" 21 . Partiendo de estos planteamientos, es digna de mención la enmienda al artículo 32 del proyecto constitucional presentada por el Diputado republicano por Lérida, Ferrer y Garcés en la que se decía lo siguiente: "Todos los poderes públicos emanan de la Nación y ninguno de ellos puede ser delegado hereditariamente» ${ }^{22}$. Éste argumentaba que la soberanía nacional o la soberanía popular, tal y como era concebida por la Escuela Democrática, le repugnaba esencial y sustancialmente la existencia de poderes permanentes ${ }^{23}$. Tras la contestación de Silvela en nombre de la Comisión y leida por segunda vez, la enmienda sería rechazada.

Destacan también las enmiendas presentadas por los Diputados De la Rosa y Caro al mismo artículo. En la enmienda del primero se afirma que "la soberania reside en el pueblo, del cual emanan todos los poderes. Éstos sólo podrán ser ejercidos por delegados». Para el autor de dicha enmienda, la emanación de una cosa podía existir sin que esa cosa fuera propiedad de quien la hacía emanar, pudiendo

18 Esta afirmación era corriente en la época, todavia no se habian producido las aportaciones doctrinales de Rudolf Smend que hacian perfectamente viable la compatibilidad de la Monarquía con la democracia.

19 En contestación al Diputado Mata, Castelar DSCC IV, 78, 20 de mayo de 1869, pág. 2130.

20 Palanca, DSCC III, 74, 14 de mayo de 1869, pág. 1966.

21 PI Y MARGALL, DSCC IV, 78, 20 de mayo, pág. 2112.

22 DSCC III, 72, 12 de mayo de 1869, pág. 1875.

23 FERRER y GaRCÉs, DSCC III, 72, 12 de mayo de 1869, pág. 1878. 
entenderse como lo hacían los legitimistas franceses que al emanar de la Nación esos poderes, el pueblo, la Nación los había perdido al entregarlos completamente en otras manos, por lo que una de las principales condiciones de la Monarquía Democrática era que el Rey fuera electivo ${ }^{24}$. Preguntadas las Cortes, tras la segunda lectura no fue tomada en consideración. Para los republicanos sólo en el primer momento de esa Monarquía, esta podía considerarse popular por cuanto debía su nombramiento a la representación nacional, a la Asamblea, pero desde el momento en que en el proyecto constitucional se consignaba el principio hereditario, "la Monarquía in futurum era lo mismo que la Monarquía in pretérito ${ }^{25}$. Sin embargo, a esta afirmación cabe objetar que, si bien la elección del monarca es el procedimiento más adecuado a seguir cuando se trata de la entronización de una dinastía en un Estado que adopte la forma de gobierno monárquica, la elección de la suprema magistratura monárquica es más propio de épocas pasadas, baste señalar, como recuerda Pérez Serrano ${ }^{26}$, el ejemplo de la Monarquía visigoda con sus frecuentes regicidios, el sistema del imperio alemán desde el Interregnum, o la Monarquía normanda de Inglaterra; porque de facto, la elección de la jefatura del Estado lo que implica es la existencia de una República, de ahi que algunos autores como Roscher hayan calificado a las Monarquías electivas como una forma republicana de tono aristocrático, o como Haller que ha señalado que se trata de revoluciones a medio terminar, casos de hermafroditismo antinacional que no pueden afianzarse mucho en el tiempo.

La enmienda del Diputado Caro iba a añadir a los delegados el carácter de temporales y responsables: «Todos los poderes emanan de la Nación, y son ejercidos por delegados temporales y responsables". Criticaban los republicanos la irresponsabilidad regia que a su juicio no era más que una ficción para seguir considerando al monarca como soberano, porque uel Rey no sería soberano si fuera responsable porque habría un poder por encima de él que le pediría cuentas de sus actos, y ese poder sería entonces el soberano" 27 . Para los republicanos la consecuencia directa del principio democrático era el derecho del pueblo para gobernarse a sí mismo y delegar sus poderes por

27 PALANCA, DSCC III, 74, 14 de mayo de 1869, págs. 1969-70. 
medio del sufragio universal, pero siempre en funcionarios amovibles y responsables. Por lo que se refiere a esta enmienda, conviene apuntar que si bien es cierto que el texto de 1869 reconocia la irresponsabilidad e inviolabilidad del monarca, no lo es menos el hecho de que el art. 67 de la Constitución va a reconocer la exigencia del refrendo ministerial para que sus actos fueran válidos, siguiendo esa máxima que dice que la responsabilidad debe estar alli donde se encuentra el poder, y el poder había pasado del Rey a sus ministros.

De una forma más accidentada fue presentada una enmienda ${ }^{28}$ a los artículos 32.3 del proyecto constitucional por el federalista Paul y Angulo, al que se le acusaría de ser el instigador del asesinato del General Prim, para que la «Nación española se gobernase por si misma, delegando su poder en un Directorio de cinco miembros nombrados por las Cortes cada tres años", que recuerda en muchos aspectos al Ejecutivo helvético. En el curso de un exaltado discurso, Paul insistió en que si las Cortes votaban la Monarquía el pueblo español volvería a batirse, y fue tal el tono violento en que lo hizo, que obligó al Presidente de la Cámara a llamarlo al orden en repetidas ocasiones, dando lugar a que el Ministro de la Guerra en nombre del Gobierno protestase de las palabras vertidas por el orador republicano, incitando al pueblo a la desobediencia en caso de que no se aprobase la República como forma de gobierno. Contestó Silvela en nombre de la Comisión, y siendo sometida a segunda lectura fue rechazada por las Cortes.

Además, los republicanos insistían en que la Monarquia hereditaria era un ataque frontal a los principios de igualdad y libertad consagrados en la Constitución. Se oponía a la igualdad porque el texto constitucional señalaba que "todos los ciudadanos son igualmente aptos para todos los cargos, y sin embargo, había uno para el que todos no eran igualmente aptos» 29 . De otra parte, la Monarquía se oponía a la libertad, porque la Monarquía representa la más viva encarnación del principio de autoridad. Por ello, importaba poco que la Monarquía cambiase de origen y en vez de ser de derecho divino fuera popular, porque la historia había demostrado que las Monarquías populares habían sido tanto o más despóticas que las de origen divino como lo demostraba las de Napoleón y su sobrino ${ }^{30}$. Los republi-

28 PAUl Y ANGUlo, DSCC III, 73, 13 de mayo, pág. 1930.

29 SORNI, DSCC IV, 76, 18 de mayo de 1869, pág. 2035.

30 PI Y MARGALL, DSCC IV , 77, 19 de mayo de 1869, pág. 2092. 
canos en la defensa de sus planteamientos, como señala Calero, iban a dar una visión deformada, caricaturesca a veces, del poder real tal como lo establecía la Constitución; y una utilización, con frecuencia arbitraria, siempre interesada de la historia negativa de las Monarquías, y en particular, de las violaciones que Fernando VII e Isabel II hicieron de la Constitución y libertad de sus súbditos ${ }^{31}$.

En defensa de la Monarquía, la mayoría gubernamental iba a utilizar como alegato principal la compatibilidad de la Monarquía y la democracia en base a dos ideas fundamentales: en primer lugar, en que el texto constitucional va a reconocer y garantizar los derechos $y$ libertades que son exigencia del principio democrático, como es fundamentalmente el sufragio universal; y en segundo lugar, que los poderes de la Corona, y el hecho de su condición hereditaria, están articulados de tal forma que no suponen un límite a la soberania del pueblo. Los miembros de la Comisión hicieron valer sus argumentos en defensa de la Monarquía formulando la teoría de la accidentalidad de las formas de gobierno ${ }^{32}$.

A diferencia de los republicanos, los monárquicos defienden que la forma es separable de la esencia. Ulloa en nombre de la Comisión llegaría a afirmar que «el carácter esencial de los gobiernos no está en las formas externas del poder, en la temporalidad o en la perpetuidad de la magistratura suprema, sino que el carácter esencial de las instituciones se encuentra en el elemento gobernante, en el elemento que constituye la soberanía, en el ejercicio de esta soberania, en su manifestación por medio del sufragio, y en la penetrabilidad de la opinión pública en el ejercicio y resultado del poder público» ${ }^{33}$. La forma de gobierno no implica, pues, el carácter esencial de éste, Montero Ríos

31 Calero, A. M. ${ }^{a}$, op. cit, pág. XXI.

32 Según Calero, esta corriente de pensamiento, de larga tradición en la historia política española, va, cuando menos, de los neotomistas del siglo XVI a la CEDA de la II República. CAlero, A. M. ${ }^{\mathrm{a}}$, op. cit., pág. XXIII.

33 Augusto UlLOA, DSCC III, 73, 13 de mayo de 1869, págs. 1914-5.

También ROMERo GIRón, quien sostendrá que las formas extrínsecas no afectan para nada la esencia del derecho, no son más que accidentes históricos que se determinan mediante motivos históricos también. La Corona y la herencia no son más que accesorios simbólicos. Curiosamente en su discusión con $\mathrm{Pi}$ durante el debate constituyente citará «El principio Federativo» de Proudhon para defender sus argumentos: «No pudiendo realizarse en toda la pureza de su ideal ni la Monarquía, ni la democracia, ni el comunismo, ni la anarquía, están condenadas a completarse prestándose la una a la otra sus diversos elementos». DSCC IV, 78, 20 de mayo, págs. 2106-7. 
afirmaría que, "toda forma de gobierno que reconozca y sancione los derechos individuales y que descanse sobre la soberanía popular, toda forma de gobierno que no mutile esos derechos y por otra parte que no oscurezca en manera alguna la soberanía del pueblo cabe dentro de la teoría democrática, no sólo no es antitética a la teoría democrática, sino que está con ella en perfecta armonia» ${ }^{34}$. Para los miembros de la Comisión, la Monarquía no perjudicaba en nada el desarrollo de la libertad, y así se ponía de manifiesto en países europeos de nuestro entorno como eran Inglaterra, Bélgica e Italia, mientras que en ciertas Repúblicas, como era el caso de los Estados Unidos, en determinados Estados del sur muchos ciudadanos tenian limitados sus derechos por el mero hecho de no ser blancos. Era por ello, que nuestro país no podía aceptar la República, "esa planta exótica que tantos y tan malos frutos ha dado en los pueblos más civilizados del mundon.

Frente a las tesis republicanas que sostenían que la democracia exigía que todos los poderes fueran electivos y temporales, los monárquicos intentarán elaborar un concepto democrático de la herencia, tratando de demostrar la compatibilidad de la democracia y la Monarquía hereditaria, y la mayor capacidad de ésta para la realización de los fines propios del Estado. Así, estos argumentaban que en la Monarquía, por más que fuera hereditaria, no había una delegación de la soberanía hasta el punto que desapareciera uno de los principios cardinales de la idea democrática, cual es la soberanía popular, porque existe una delegación no perpetua sino indefinida de la soberanía, sería una delegación de soberanía pero nunca una abdicación ${ }^{35}$. Sin embargo, se partía de un error inicial dado que en ningún caso podía considerarse que

34 Montero Ríos, DSCC IV, 76, 18 de mayo de 1869, pág. 2026.

35 En este sentido, MONTERo Rios decía lo siguiente: "Lo único que quedará será una delegación de carácter indefinido, una delegación temporal, como delegación temporal sería la que vosotros habriais de hacer en el Presidente de vuestra República. Es cuestión de tiempo; vosotros podríais hacer una delegación por cinco, diez o veinte años, y nosotros la haremos por veinte o cuarenta, por tiempo indefinido, pero no enajenaremos la soberanía, la delegaremos tan sólo». DSCC IV, 76, 18 de mayo de 1869, pág. 2027.

También Cirilo Álvarez cuando afirmaba que uel principio de la soberanía nacional, consiste en el derecho que tienen las Naciones de gobernarse a si mismas, de constituirse a si mismas, de decretar la organización de sus poderes públicos, (...) el principio de soberanía nacional no se opone, no es incompatible con la delegación de ese poder a una dinastía, a una familia, cuando los poderes públicos se organizan por medio de la forma monárquica", porque no se trataba de una delegación perpetua sino indefinida. DSCC IV, 77, 19 de mayo de 1869, pág. 2082. 
había una delegación de soberanía hacia el monarca, el único representante de la soberanía del pueblo era el Parlamento elegido por sufragio universal, pero en ningún caso el monarca.

Fue don Antonio de los Ríos Rosas quien introdujo la tesis de la elección limitada para justificar que la herencia puede existir en un Estado libre si se compagina con la elección, al señalar que la delegación de soberanía se renovaba mediante el requisito de la jura exigido al Rey y al Príncipe de Asturias, pudiendo las Cortes, como representantes de la soberanía nacional, excluir del Trono a aquellas personas que no reuniesen las condiciones adecuadas o fueran incapaces $^{36}$. En la intervención de Ríos Rosas se puede apreciar una cierta inclinación doctrinaria en sus planteamientos, y es que como dice Calero ${ }^{37}$, algunos de los constituyentes no dudaron en hacer una presentación democrática del concepto doctrinario de la soberanía nacional, combinado con el principio de la representación. Quizás esto es todavía más patente en el Diputado conservador Cánovas del Castillo ${ }^{38}$ para quien «existe una relación incontestable, segura, $y$ evidente entre la Monarquía y sus principios hereditarios, y la continuidad del principio social. La Monarquía hereditaria representa mejor que ninguna otra institución esa continuidad del principio social, dice el político malagueño, porque "guarda en depósito el caudal de las generaciones pasadas para las venideras, siendo el instrumento más grande del progreso y desenvolvimiento histórico de una Nación. Es por esto, que la forma más perfecta, principalmente atendiendo al desarrollo legítimo de la personalidad humana y a la consagración histórica de los derechos individuales, será la forma monárquica».

Por último, los monárquicos de 1869, al igual que hicieran Mably - De Lolme, y más tarde Max Weber tratarán de relacionar el principio hereditario con la función moderadora, "préservative et réparatrice», propia de la jefatura de Estado monárquica diseñada por Constant.

36 DSCC IV, 78, 20 de mayo de 1869, pág. 2137. "Ved aquí cómo se compaginan la soberanía nacional (...) y la herencia limitada por la elección. El Rey (...) representa a la generación que les elige y a las generaciones futuras (...) porque en cada vacante acumula la soberanía nacional de la generación presente a la soberanía nacional de la generación pasada; (...) este es el gran prestigio de la Monarquía hereditaria que representa la soberanía nacional actual, la soberanía nacional pasada, la soberanía nacional futura, la soberanía nacional continua (...). Y así representa la perpetuidad del Estado y la eternidad de la patria».

37 CALERO, A. M. ${ }^{a}$, op. cit., 1987, pág. XXV.

38 CAnovas del CASTILLo, DSCC II, 44, 8 de abril de 1869, págs. 936-7. 
Nuevamente sería Ríos Rosas ${ }^{39}$ quien intentará justificar el principio hereditario como el más adecuado garante de la neutralidad e imparcialidad de la institución monárquica. De esta manera, "la autoridad más impersonal, la autoridad que no recibe su misión de ninguna mayoría, la autoridad que no la recibe de partido, la autoridad que la recibe inmediatamente de la ley, la autoridad que sólo tiene que entenderse con los partidos, con las Cámaras, con las mayorías en calidad de poder moderador, la autoridad que no espera la reelección, la autoridad que no tiene que corromper para ser reelegida, esa autoridad es más natural, más imparcial, esa autoridad es más impersonal que cualquier otra".

\section{LA FORMA DE GOBIERNO MONÁROUICA EN LOS MODELOS POLÍTICOS COMPARADOS Y LA REVOLUCIÓN DE 1869}

El componente utópico de la Revolución de Septiembre de 1868, esa creencia en la igualdad esencial de todos los hombres, en el pacifismo, en la emancipación de los pueblos coloniales, en la abolición de la esclavitud etc., la convirtieron en un modelo a imitar y objeto de admiración en Europa donde a la vez se temía que los sucesos revolucionarios de España se extendieran por toda ella en una nueva oleada revolucionaria al igual que ya ocurriera en 1820 .

Los defensores del proyecto constitucional eran conscientes de que la forma de gobierno republicana alarmaría en Europa fundamentalmente monárquica, este era el caso de Portugal, Inglaterra, Holanda, Bélgica, Rusia, también predominaban los monárquicos en Alemania e Italia (en los que todavía no se habían producido sus procesos de unificación), y los imperialistas en Francia. Los republicanos sólo podían contar con "la estéril simpatía" de las tres únicas Repúblicas de Europa, Suiza, Andorra y San Marino ${ }^{40}$. También los republicanos eran conscientes de la reacción que podía generarse en Europa contra la proclamación de una República en España, Figueras ${ }^{41}$, parafraseando a Danton decía que uun pueblo en ebullición no ha de temer el contacto de los demás pueblos, ellos son los que han de temer el suyo", y es que lo acontecimientos acaecidos en España eran vis-

39 Ríos Rosas, DSCC II, 45, 9 de abril de 1869, pág. 960.

40 SilLVELA, DSCC III, 75, 17 de mayo, págs. 1997-8.

41 Figueras, DSCC IV, 76, 18 de mayo, pág. 2055. 
tos con preocupación por el resto de los paises europeos temerosos de un nuevo brote revolucionario.

Las referencias a la historia política de otros países de nuestro entorno fueron constantes durante todo el debate constituyente tanto por parte de los diputados monárquicos como de la minoría republicana a la hora de intentar justificar sus pretensiones. Así, para los republicanos no existían precedentes históricos que mostrasen que un pueblo, encontrándose en la situación en que se encontraba el nuestro, después de haber expulsado a una Reina tras una revolución, se hubiese dado a sí mismo una dinastía extranjera. Estos sostenían que en el caso de Bélgica la dinastía extranjera había sido impuesta por la Conferencia de Londres, lo mismo que la de Grecia que había sido impuesta por la diplomacia, sin olvidar los trágicos sucesos de México con la imposición de Maximiliano "por la fuerza de las bayonetas" 42 . No obstante, si bien es

42 Soler, DSCC III, 73, 13 de mayo, pág. 1933.

Ciertamente la intervención extranjera, sobre todo inglesa y francesa, en la promoción de estas candidaturas fue determinante. Así en Grecia, tras el Protocolo de Londres de 1830 que creaba una Grecia independiente bajo una Monarquía hereditaria, se ofrece el Trono a Leopoldo de Sajonia-Coburgo, quien lo rechaza, ocupándolo finalmente Otón I de Baviera hasta la insurrección de 1863 favorecida por Inglaterra quien propone la candidatura de Guillermo Jorge de Glücksbourg, Jorge l, de la Casa danesa de Schleswig-Holstein.

En el caso de Bélgica, quizás el supuesto que guardaba más similitudes con el caso español, su Gobierno provisional había nombrado una comisión encargada de redactar un proyecto de Constitución que se publicaba el 28 de octubre de 1830 justo el mismo dia en que los holandeses bombardeaban Amberes. La citada comisión había adoptado la forma monárquica por ocho votos contra uno. El 10 de noviembre se inauguraba el Congreso Nacional belga que el 22 de noviembre de 1830 se declara por 174 votos contra 13 a favor de la Monarquía constitucional. El 3 de febrero siguiente tras cinco días de discusión se procedía a la votación del Rey. Circulaban en Bélgica, como en 1869 en España, varias candidaturas regias, tres de ellas fueron objeto de votación de los diputados constituyentes, sin embargo, ninguna de ellas llegaría a realizarse. El Duque de Nemours obtuvo 97 votos; el Duque de Leuchtenberg 74 y Carlos de Austria 21. El Duque de Nemours fue proclamado por la Asamblea, y una comisión de ésta, compuesta de diez diputados, salía el 10 de febrero a parís a ofrecer al Duque la Corona de Bélgica. Luis Felipe rehusó en nombre de su hijo con frases altamente lisonjeras y simpáticas hacia Bélgica y fundándose en uno de los artículos del protocolo de la Conferencia de Londres de 4 de noviembre de 1830. Descartando los presuntos derechos al Trono de la casa Nassau-Orange, y tras votar la Constitución de 7 de febrero de 1831 ofrece el título de "Rey de los belgas» a Leopoldo de Sajonia Coburgo-Gotha, candidato protegido de Gran Bretaña, casado con María Luisa de Orleáns, hermana del Duque de Montpensier. Era el 22 de abril de 1831 cuando Leopoldo de Sajonia Coburgo recibia en Inglaterra, en Malborough House, a la comisión de cuatro diputados que enviaba la Asamblea belga para tener con él una conferencia 
cierto que la intervención de la diplomacia extranjera había sido decisiva en la instauración de estas nuevas dinastías, no es menos cierto que nuestro país tampoco escapó a las tradicionales influencias de Francia e Inglaterra, y a las consultas y presiones de las distintas Chancillerías extranjeras a la hora de la elección de un candidato al Trono español. En este sentido, recuérdese la oposición de Francia a la candidatura de Montpensier, por la negativa de su Emperador a que un Orleans fuera Rey de España., o el escaso entusiasmo de los Gobiernos de París y Londres por la candidatura de don Fernando de Coburgo ante una posible Unión Ibérica. Todo ello sin olvidar, que será una de las candidaturas al Trono español, la de don Leopoldo de Hohenzollern-Sigmaringen, yerno del Rey viudo de Portugal, la excusa que desencadenaría la guerra franco-prusiana auspiciada por Bismarck tras el famoso telegrama de Ems.

Por el contrario, los defensores del proyecto constitucional manifestaban que la historia política de distintos países europeos si daba ejemplos del establecimiento de la institución monárquica después de períodos de fuerte convulsión revolucionaria. Así, había sucedido en Inglaterra en 1688 tras la "Glorious Revolution" que destronó a Jacobo II de Estuardo donde en vez de adoptar la República se ofreció el poder a un príncipe extranjero, yerno del Rey, rival poco antes, que era Guillermo de Orange. Holanda que vivía bajo una República con Juan Witt, cambió de forma de gobierno y adoptó la Monarquía, también con Guillermo de Orange. De la misma manera, Suecia tras la Revolución de 1809 en vez de proclamar la República buscó un soldado de fortuna en el extranjero para coronarlo. También Francia en 1830, después de arrojada la rama legítima se va a buscar la rama segunda, la de los Orleans, para que no hubiera solución de continuidad entre la Monarquía que caía y la que se levantaba ${ }^{43}$.

antes de proceder a la votación. Leopoldo, que ya había rehusado el Trono de Grecia, puso algunas dificultades a causa de las cuestiones territoriales del Luxemburgo y Limburgo que formarían parte de la Confederación Germánica, pero allanado este conflicto por la votación de la Constituyente que adoptó los 18 artículos de la Conferencia de Londres, la votación del Rey tuvo lugar el 4 de junio de 1831 siendo elegido por 157 votos contra 39. El 21 de julio siguiente juraba el Rey Leopoldo la Constitución en Bruselas y cesaba en sus funciones la regencia.

También en el establecimiento del Archiduque de Austria Maximiliano como Emperador de México jugó un papel decisivo la diplomacia internacional tras el Tratado de Londres de 1861 hasta los trágicos acontecimientos de Querétaro tan presentes en la elección de un candidato al Trono español ante el temor de las Casas reales europeas por la particular situación política que vivía nuestro país. Ello se hizo patente con la negativa del Duque de Génova, don Tomás de Saboya.

43 ULLOA, DSCC III, 73, 13 de mayo, pág. 1917. 
Todo ello se encontraba íntimamente ligado al significado último que para las distintas fuerzas políticas había tenido la Revolución de Septiembre de 1868 respecto de la cuestión de la forma de gobierno. Para los progresistas, y los hombres de la Unión Liberal, la Gloriosa había supuesto únicamente la caída de la dinastía Borbón, pero no significaba, ni mucho menos, la supresión de la institución monárquica. Estos sostenían que en España no había ocurrido otra cosa que lo que ya ocurriera en 1688 en Inglaterra con la dinastía de los Estuardos, o en 1809 en Suecia con la dinastia Holstein-Gottorp, o en Francia con la dinastía de Carlos $X$ en 1830, y como habían sucedido en 1860 y 1861 con las dinastías de Nápoles, Parma, Módena y Toscana que fueron reemplazadas por otras dinastías con los mismos intereses revolucionarios que habían derrocado aquellos Tronos.

La Junta de Bruselas de 30 de junio de 1867 en la que se aceptarán una serie de bases, que por otra parte, ya habian sido aceptadas en el Pacto de Ostende el 22 de agosto de 1866, afirmaría que el objeto y bandera de la Revolución sería la caída de los Borbones. No se hacía, pues, referencia alguna a la caída de la Monarquía, sino únicamente al derrocamiento de la dinastía que representaba Isabel II.

En la alocución dirigida por el Almirante Juan Bautista Topete el 17 de septiembre de 1868 en la misma bahía de Cádiz se decía "aspiramos a que las Cortes Constituyentes (...) acuerden cuanto conduzca al restablecimiento de la verdadera Monarquía constitucional». El fin intrínseco de la Revolución de Septiembre era la expulsión de la dinastía que representaba la Monarquía doctrinaria de Isabel II para reemplazarla por otra dinastía exponente de una nueva Monarquia que nacía de la legitimidad democrática que le confería la Constitución de 186944. Es más, en el manifiesto de Cádiz únicamente se decía «Abajo Isabel II y toda su descendencia", fue la Junta de Madrid primero, y más tarde algunas otras las que extendieron la proscripción y dijeron "Abajo los Borbones", sin que esto quisiera decir abajo los Reyes ${ }^{45}$. Pero es que, además, ninguno de los ilustres Generales que habían preparado y liderado la Revolución de Septiembre deseaban el triunfo de la República ${ }^{46}$.

44 Olózaga, DSCC IV, 76, 18 de mayo, pág. 2039.

45 SilvelA, DSCC III, 75, 17 de mayo, pág. 1992.

46 Cirilo ÁlvareZ, DSCC IV, 77, 19 de mayo, pág. 2085. "Al pronunciarse en la fragata Zaragoza los ilustres Generales iniciadores de la Revolución. ¿Se acordaron de la República? (...) En el programa de Cádiz ¿hay algo de República?, ¿lo hay en el programa de Sevilla? Las juntas revolucionarias, incluso la de Madrid 
Por el contrario para la minoria republicana, la Revolución de Septiembre se había hecho al grito unánime de "Abajo lo existente", y lo existente no era otra cosa que la Monarquía doctrinaria borbóni$\mathrm{ca}^{47}$. De esta manera, para los republicanos, cuando el pueblo derribó a los Borbones, no sólo se había expulsado a la Reina y toda su descendencia, sino que también se había derribado la Corona de España. Sin embargo, como ya expusiera el Gobierno Provisional en su manifiesto de 25 de octubre de 1868, ningún programa de las distintas juntas revolucionarias se había decantado abiertamente por la forma de gobierno republicana: "todas las juntas, expresión genuina de aquel movimiento, han proclamado los principios cardinales de nuestra nueva organización política; pero han guardado silencio sobre la institución monárquica", lo cual era lógico si se tiene en cuenta el control de las mismas en la mayoría de los casos lo iban a tener los hombres de la Unión Liberal y del Partido Progresista firmes partidarios de la forma de gobierno monárquica. En el programa que en Madrid publicó el suplemento de "Las Novedades" de 29 de septiembre, se abre del siguiente modo: "Abajo la dinastía. Monarquía constitucional y Cortes Constituyentes como medios; la unión ibérica como fin". Las dos primeras Juntas andaluzas en constituirse fueron las de Sevilla y Málaga formulando como uno de los objetivos de la Revolución de Septiembre el destronamiento de la dinastía, en ningún caso la proclamación de la República. En Cataluña el Comité Revolucionario de Barcelona publicó el 20 de septiembre un manifiesto en el que se abogaba únicamente por derribar la dinastía existente. La Junta Revolucionaria de Cartagena en un comunicado el 28 de septiembre en el explicaba al pueblo su programa no entraba a prejuzgar la forma de gobierno que habría de regir al pais, sólo excluía a la dinastía borbónica. Como excepciones a lo expuesto nos encontramos con la Junta

¿escribieron en sus programas la bandera de la República? Es verdad que dijeron "abajo lo existente", ¿pero se quiere suponer por eso que la Revolución de Septiembre venía a no dejar en el país restos de una Monarquía secular, de una institución que había presidido sus destinos por espacio de siglos? Es imposible. La idea republicana nació mucho después".

47 SerRaClara, DSCC III, 75, 17 de mayo, pág. 1984. "Lo existente era una Monarquía centralizadora, una Monarquía que anulaba la vida de las provincias, y del municipio (...) lo existente era una Monarquía que concentraba en si todas las fuerzas de la Nación; que tenía un ejército numerosísimo a su disposición, no para bien de la patria, sino para el bien de si misma; que necesitaba un ejército de empleados que le cantasen alabanzas y la quemaran incienso; que sostenía con la Iglesia católica relaciones muy íntimas para venir a dominar no sólo en lo material, sino también en el terreno de las conciencias, y a inclinar por este medio a los súbditos al camino que ella creia contrario a la libertad". 
de Santander, donde el Comité Republicano, dirigido por el Brigadier de marina Chacón se sublevó el 19 de septiembre a los gritos de ¡Viva la libertad!, ¡Viva la República!, ¡Abajo los Borbones!, sobreponiéndose a progresistas y unionistas, y logrando constituirse en junta, se pronunció expresamente a favor de la forma de gobierno republicana, aunque por un breve espacio de tiempo porque el 24 de septiembre la ciudad fue sometida por las tropas del General Calonge ${ }^{48}$; y la Junta de Jerez de la Frontera que abogó por el establecimiento de una República descentralizada.

El silencio sobre la institución monárquica que mantuvieron las juntas, fue tomado por el Gobierno Provisional en el manifiesto dirigido a la Nación de 25 de octubre de 1868, "no como un argumento favorable, sino como dato digno de tenerse en cuenta para resolver con acierto problema tan trascendental y difícil», porque las juntas «no han confundido, a pesar de lo fácil que era en horas de perturbación apasionada, las personas con las cosas, ni el desprestigio de una dinastía con la más alta magistratura que simboliza». El Gobierno Provisional se va a manifestar abiertamente partidario de la forma monárquica aunque " si se equivocase en sus cálculos y la decisión del pueblo español no fuese propicia al planteamiento de la forma monárquica, respetaría el voto de la soberanía de la Nación, debidamente consultadan.

Nuevamente en el preámbulo del Decreto de 6 de diciembre de 1868 en el que se fija la fecha de la elección a Cortes Constituyentes los días 15 al 18 de enero de 1869 y la apertura de la Asamblea para el 11 de febrero siguiente, se puso de manifiesto el favoritismo del Gobierno por la causa monárquica, mostrando su ya conocida preferencia por la "forma monárquica con sus atributos esenciales" y celebrando uque salgan victoriosos de las urnas los mantenedores de ese principio $y$ del hecho de un monarca, no electivo, sino elegido por aquellos a quienes el pueblo español otorgue al efecto sus poderes".

Finalmente, con el nuevo manifiesto del Gobierno Provisional de 11 de enero de 1869, cuatro días antes de las elecciones, el Gobierno vinculaba su futuro al de la nueva Monarquía, cuando sostenia que «salvo el respeto a la suprema decisión de las Cortes Constituyentes, juzga el Gobierno que tienen más seguro porvenir las instituciones

48 MOLINER, A., "La Revolución Burguesa y Movimiento Juntero en España. La acción de las juntas a través de la correspondencia diplomática y consular francesa 1808-68", pág. 327. 
liberales garantizadas'en la solemne y sucesiva estabilidad del principio monárquico, que sometidas al peligroso ensayo de una forma nueva, sin precedentes históricos en España y sin ejemplos en Europa dignos de ser imitados".

\section{EL PLEBISCITO SOBRE LA CUESTIÓN DE LA FORMA DE GOBIERNO}

Durante el debate constituyente la cuestión de someter a plebiscito la forma de gobierno sería defendida por el Diputado por Alcoy, don Buenaventura Abárzuza. A tal objeto fue presentada por el federalista Fernando Garrido una enmienda de adición al artículo 32, en la que se pedía que después de las palabras «Todos los poderes emanan de la Nación" se añadiría "y por consiguiente, así la forma de gobierno como la persona del jefe del Estado serán objeto de un plebiscito $49^{\prime \prime}$.

La convocatoria de un plebiscito para decidir sobre la forma de gobierno no era algo nuevo. Ya en la reunión de la Junta de Bruselas celebrada el 30 de junio de 1867 en una de las bases que fueron aprobadas se convino que la forma de gobierno se decidiría por plebiscito o por una Asamblea Constituyente. También Olózaga había propuesto en los primeros días de la Revolución de 1868 que fuera el pueblo el que decidiera sobre la forma de gobierno, sin embargo, esto no fue apoyado por los republicanos en aquel momento conscientes de las escasas posibilidades de un resultado favorable a sus intereses en los primeros momentos de la Revolución ${ }^{50}$. Por ello, las juntas revolucionarias con fuerte componente republicano como era el caso de la Junta Revolucionaria de Madrid, integrada por algunos federales como Chao, Sorní, Figueras, Orense y García López, cuando en el mes de octubre de 1868 se debatió sobre esta cuestión, se decidió que la forma de gobierno fuese establecida, y el jefe del Estado elegido por las Cortes Constituyentes y no a través de un plebiscito. En este mismo orden de cosas, la Junta Revolucionaria de Sevilla, formada entre otros por destacados federales como Federico Rubio, Pérez del Álamo, De la Rosa, protestó contra el periódico madrileño La Época por difundir la idea de plantear un plebiscito para decidir la cuestión de la forma

50 Olózaga, DSCC IV, 76, 18 de mayo, pág. 2040. 
de gobierno; protesta a la que se sumaron también diversos periódicos sevillanos como El Porvenir, Andalucía, El Clarín, Boletín de Anuncios, La Giralda, El Universal, El Demócrata y Las Novedades 51 . En el debate constituyente de 1869 , los republicanos intentaron justificar de manera poco satisfactoria su oposición al plebiscito en la Junta Revolucionaria de Madrid tratando de ocultar la auténtica causa que les impulsó a adoptar esta decisión ${ }^{52}$. Ciertamente durante los primeros momentos del proceso revolucionario los republicanos eran conscientes de que un plebiscito sobre la forma de gobierno hubiera sido adverso para sus intereses, debido a su escasa fuerza en la opinión pública, motivo por el cual se mostraron radicalmente en contra. Sin embargo, una vez iniciado el debate constituyente, $y$ a medida que la posición republicana se afianzaba, teniendo en cuenta, además, que la situación de interinidad por la que atravesaba el país jugaba a su favor, sus argumentos cambiaron. Figueras se arrepintió de no haber presionado más para la celebración de un plebiscito previo que decidiera sobre la forma de gobierno dado que "cuanto más se prolongara la ausencia de un Rey, era ya un triunfo para los republicanos que podían demostrar a España y al mundo entero que la República era posible con orden y con justicia»53. Para estos la República duraba ya desde hacía siete meses ${ }^{54}$, la República en España era posible, porque "era pura y simplemente la legalización de lo existente» ${ }^{55}$. Como diría Castelar, del plebiscito celebrado en estas nuevas circunstancias salía indudablemente o la República o la Monarquía del General Espartero ${ }^{56}$. Finalmente sometida a votación nominal la enmienda sería rechazada por 157 votos contra 50 .

51 MOLINER, A., op. cit., pág. 309.

52 DSCC III, 74, 14 de mayo, pág. 1961. Así, lo exponía GaRCí LÓPEZ: “Nos opusimos entonces porque los que deseamos la proclamación y conservación de la República federal queremos que sea votada y aceptada en situación normal por los ciudadanos que obren en conciencia propia, sabiendo lo que van hacer, y no emitiendo su voto en momentos de extraordinario entusiasmo, cuales son los que siguen inmediatamente a una revolución. (...) Además de esta razón tuvimos otra (...). En aquella situación los elementos conservadores puede decirse que no existían (...) y se hubiera dicho (...) que nos habíamos aprovechado de aquellos momentos para establecer una forma de gobierno que ellos rechazaban».

53 Figueras, DSCC II, 42, 6 de abril, pág. 869.

54 ORENSE, DSCC III, 73, 13 de mayo, pág. 1899. "No olvidéis que la República dura hace siete meses en España, y aunque no ha sido muy buena, esto no esculpa de la idea, porque para tener una República buena es preciso que también lo sea el gobierno, toda vez que como decia el señor Castelar, ya no hemos acostumbrado a pasarnos sin Reyn.

55 GIL BERGES, DSCC III, 75, 17 de mayo, pág. 2019.

56 Castelar, DSCC II, 45, 9 de abril, pág. 952. 


\section{LA MONARQUÍA DEMOCRÁTICA}

Como ya apuntamos anteriormente, las Constituyentes de 1869 diseñaran una verdadera teoría de la Monarquía democrática en respuesta a las acusaciones de la minoría republicana. La Monarquía de 1869 supondrá una auténtica ruptura con la anterior Monarquía doctrinaria mantenida desde 1834 , que nuevamente será restaurada en 1874.

Fue el progresista, don Victor Balaguer quien en la sesión del 14 de mayo de 1869 propuso que a la Monarquía establecida por la Constitución se la calificase expresamente de democrática: «Si, yo deseo que venga una dinastía nueva, creo también que esta dinastía ha de venir rodeada de un gran prestigio popular, y este sólo podrá tenerle; dándole a la Constitución que estamos redactando una forma verdaderamente democrática, y estableciendo de una manera que no pueda dejar lugar a dudas, la Monarquía democrátican. Aunque tal denominación triunfó durante el Sexenio, sin embargo, no se incorporó al texto constitucional. En ocasiones también se emplearon los términos de Monarquía popular o Monarquía liberal para referirse a la nueva Monarquía que nacería de la Constitución de 1869. Sería don Fermín Lasala, Duque de Mandas, quien introdujera el término de Monarquia popular, término que también sería empleado por otros diputados como el demócrata don Cristino Martos, para quien la Monarquía popular sería "una Monarquía de verdad en que sea cierta en todos sus extremos una definición célebre de la Monarquía moderna, la acción moderadora de uno solo en medio del gobierno de todos, con la herencia como condición y la estabilidad como consecuencia» ${ }^{57}$.

Para Balaguer, eran las tradicionales Monarquías paccionadas de Aragón y de Castilla el auténtico origen de la Monarquía democrática de 1869: "¿Qué eran sino democráticos, en toda la verdad y realidad de la palabra, aquellos antiguos e ilustres Reyes de Castilla, León, de Aragón y Cataluña, de Sobrarve y de Navarra? ¿Cómo puede negarse el sello más esencial de democratismo a unos Estados que tenían leyes paccionadas, a unos Estados que tenían consignado en sus leyes el derecho de insurreccionarse contra el poder real en caso de contra-fuero, a unos Estados que, como Cataluña, tenían consignado en su Constitución el que fuese ley inapelable e ineludible lo que se votase en las Cortes dentro las seis horas posteriores a haber sido disueltas por ese 
Rey, a unos Estados, en fin, que, como el de Aragón, levantaban sobre el Rey, representada en su Gran Justicia, la soberana majestad del pueblo" ${ }^{58}$. Como ha venido siendo una constante en nuestra historia constitucional, se va a invocar la tradición política española para buscar los orígenes de la nueva Monarquía, la llamada Monarquía democrática ${ }^{59}$.

De manera poco apropiada, Balaguer fundamentó la nueva Monarquía democrática en la teoría del pacto constitucional: "yo creo que para la Monarquía que vamos a fundar hemos de hacer un Rey a la usanza de la antigua Castilla, a la usanza de los de la Corona de Aragón, que sea el primero y supremo magistrado del pais; pero que esté sujeto con un anillo de hierro a las prescripciones inviolables del pacto constitucional. (...) Al Rey que faltaba al pacto, al Rey que hollaba y quebrantaba las libertades del país le arrojaban y le despojaban del Trono por medio de pregones públicos, declarándole traidor a la patria, como sucedió en Cataluña, primero con Juan II, después con Felipe IV, y más tarde con Felipe $V$; y se iban tranquilamente a buscar otro Rey, sin necesidad de pensar en la forma republicana, pues la creían, y era verdad, forma de gobierno inferior a la monárquico democrática para guardarles y para garantizarles su libertad. (...) La Constitución es el pacto entre el monarca y el pueblo. (...) Poco me importa el monarca; este vendrá cuando convenga, cuando queramos, cuando lo necesitemos. Y sobre todo, en mi pobre opinión, el monarca no debe venir hasta que hayamos hecho la Constitución, hasta que le podamos proponer el pacto por medio de la antigua fórmula aragonesa: si non, non. (...) Cuando se celebró el Parlamento de Caspe, que era una situación parecida, igual, casi idéntica a la que hoy estamos atravesando, la Corona de Aragón, después de haber votado la forma monárquica estuvo dos años sin Rey. De esta manera, la nueva Monarquía que se trataba de instaurar era la «Monarquía democrática, Monarquía rodeada de formas democráticas, Monarquía que sea hija de la soberanía nacional, que sea directamente el fruto del espíritu del país, Monarquía

58 Rectificación DSCC $n .^{\circ}$ 74, sesión de 14 de mayo de 1869, pág. 1942. Enmienda del Sr. Balaguer; debió ponerse lo siguiente: «La forma de gobierno de la Nación española es la Monarquía democrática». DSCC 20 de mayo de 1869, tomo IV, n. ${ }^{\circ} 78$, pág. 2147.

59 JOVER hace referencia a la reiterada invocación a una tradición política por parte de los constituyentes desde Cádiz hasta Franco. Ya Martínez Marina se preocupa de enlazar la obra de Cádiz con la vieja tradición liberal de las Cortes castellanas $y$ aragonesas cuyas libertades habian sido aniquiladas por los Austrias $y$ Borbones. Historia de España de MENÉndez PeLAYo, tomo XXXIV, «La Era Isabelina y el Sexenio Democráticon, pág. 304. 
a que pueda llamarse verdaderamente popular, como lo eran aquellas nuestras antiguas Monarquias que tanta gloria han dado al mundo $y$ que han sido la maravilla de la historia y el asombro de naciones extranjeras" 60 .

La crítica más rigurosa y acertada a los planteamientos de Balaguer provino del Presidente de la Comisión Constitucional, Olózaga. En la Monarquía paccionada el monarca era uno de los poderes soberanos junto con el pueblo, en la Monarquía democrática, la Monarquía es un poder constituido y no soberano. El origen de la Monarquía democrática no podía estar, pues, en las Monarquías paccionadas de la Edad Media, porque, como señalaba Olózaga61, "entonces el Rey por sí solo era una parte, la Nación no era más que otra. Ahora la Nación es todo; ahora constituimos el país como entendemos que el país debe estar constituido, como quiere ser constituido, y no necesitamos pacto ninguno. Hacemos la Constitución como cumple a los legisladores españoles, sin consideración de ninguna especie a la voluntad del monarca, que pudiera por su parte exigir otras condiciones $\gamma$ no aceptar las que le propusiéramos. La Nación se constituye a sí misma; la Nación elegirá a un monarca, y le dirá: la ley es esta, no tienes más que aceptarla y cumplirla después. (...) la esencia del compromiso de Caspe de las Cortes Constituyentes, en que los compromisarios no tenían el derecho de elegir Rey, sino el de decidir quien de los pretendientes tenía mejor derecho a la Corona, y aqui no reconocemos derecho ninguno nada más que el interés de la Nación".

Otro de los defensores del artículo 33 del proyecto constitucional, y miembro de la Comisión Constitucional fue el unionista don Augusto Ulloa y Castañón, quien en su contestación al discurso del Marqués de Albaida vendría a defender la Monarquía, «pero no la Monarquía de derecho divino, no la Monarquía de origen dinástico ni familiar, sino la Monarquía que se deriva del sufragio universal, la Monarquía que tiene por base la soberanía nacional, y por objeto la consolidación de la libertad, la salvaguardia de todos los derechos que están consignados en la Constitución del Estado». Para ello, se proponía demostrar la veracidad de tres proposiciones cuya afirmación, a su juicio, echaba por tierra los argumentos expuestos por el Marqués de Albaida a favor de la República federal. La primera de estas proposiciones era que "la libertad no necesita para desenvolverse de una

60 Balaguer, DSCC III, 74, 14 de mayo de 1869, págs. 1943-4.

61 OlOzaga, DSCC III, 73, 13 de mayo, pag. 1945. 
forma de gobierno determinada». En relación a esta primera proposición, para Ulloa, la libertad estaba garantizada en tanto en cuanto los derechos y libertades estaban reconocidos y garantizados en el texto constitucional de 1869 , independientemente de cual fuera la suprema magistratura que cerrara la cúspide del edificio constitucional que nada nuevo añadía a éste respecto ${ }^{62}$.

La segunda proposición manifestaba que "la forma de gobierno no marca por sí sola el carácter, ni la esencia de las instituciones políticas ${ }^{63}$; ese carácter, esa esencia están en los elementos gobernantes, en los elementos constitutivos de la soberanía y en su ejercicio. Respecto de esta proposición, para el Diputado gallego de la Unión Liberal, en la República no era de esencia la democracia, se volvía de esta manera a la tesis de la accidentalidad de las formas de gobierno. La República podía ser tan absoluta como la Monarquía y par demostrar esta afirmación acudía a los ejemplos históricos dados por las antiguas Repúblicas griegas, la misma República romana, las Repúblicas medievales italianas, la República de Cronwell, o incluso la Convención con la dictadura de Robespierre, el Consulado de Bonaparte o la República de 1848. La única nota verdaderamente diferenciadora entre uno y otro tipo de magistratura era la temporalidad del poder supremo sometido a la elección en el caso de la República, y la perpetuidad del mismo en la Monarquía a través de la herencia ${ }^{64}$. Frente a los ejemplos anteriores de Repúblicas autoritarias, el político unionista acudirá al ejemplo de la Monarquía inglesa, paradigma de libertad, para la defensa de su proyecto65.

62 DSCC III, 72, 12 de mayo de 1869, pág. 1912: “(...) la libertad consiste en el reconocimiento, en la extensión y en la garantía de los derechos individuales, en la soberanía del ciudadano para todo aquello que es individual, y en la reserva para el Estado de todo aquello que es indiviso".

63 Ya en el mitin del Circo Price en octubre de 1868, Martos había hablado en oposición a Figueras de la accidentalidad de las formas de gobierno.

64 ULLOA, DSCC III, 13 de mayo de 1869, 73, págs. 1912-4. «La República y la Monarquía se distinguen por un conjunto de rasgos, y uno de ellos para mi el más importante, el que forma verdadera fisoncmia, es el siguiente: la temporalidad del poder supremo por medio de la elección en la República y la perpetuidad de la suprema magistratura por medio de la herencia en la Monarquía. Pero aparte de esto, la República puede vivir, ha vivido en las oligarquías y en las aristocracias. (...) La República, en fin señores, puede ser tan absoluta como la Monarquía. (...)").

65 ULLOA, DSCC III, 73, 13 de mayo de 1869, pág. 1914 «con la unidad y la Monarquía hemos ganado nuestra independencia, que con la unidad y la Monarquía nos hemos engrandecido, que con la unidad y la Monarquía hemos conquis- 
Por último, la tercera proposición sostenia que ula Monarquía es la institución que asegura y garantiza mejor la libertad en España, la que representa su unidad nacional, la que concuerda con sus tradiciones, con sus sentimientos y sus necesidades, y la que encaja perfectamente en el sistema europeo en el que tenemos que seguir viviendo so pena de aislamiento" 66 .

Curiosamente, y aun siendo Ulloa uno de los defensores de la Monarquía democrática, y por tanto, de una Monarquía diferente a la Monarquía doctrinaria precedente, sin embargo, en algunos momentos del debate, parece aceptar la tesis de la Constitución interna, al reconocer la existencia de dos poderes históricos ${ }^{67}$.

A lo largo de todo el debate constituyente, los defensores del artículo 33 del proyecto constitucional, trataron de diferenciar la nueva Monarquía democrática que se pretendía instaurar nacida de unas Cortes Constituyentes, de la Monarquía doctrinaria o Monarquía moderada precedente que había sido derribada. $Y$ es que la minoría republicana no tardó en tratar de encontrar similitudes entre la Monarquía isabelina y la Monarquía del proyecto constitucional. En primer lugar, a juicio de los republicanos, la nueva Monarquía al igual que la anterior iba a participar en el poder legislativo gracias a la prerrogativa de la sanción de las leyes que el proyecto constitucional reconocia al monarca; además, al igual que en anteriores Constituciones españolas en que se atribuía al Rey el mando de las fuerzas de mar y tierra, el texto de 1869 también reconocía el mando de mar y tierra al futuro monarca; e incluso el derecho de gracia que tenía Isabel II de indultar a los criminales, también lo iba a tener el monarca que viniese ${ }^{68}$. Sin

tado la mitad de Europa, hemos descubierto y colonizado medio mundo, (...) la Monarquia nos ha representado en todas partes, $Y$ esto ¿qué significa? Que entre nosotros hay una verdadera constitucionalidad entre la Nación y la Monarquía".

66 DSCC III, 72, 12 de mayo de 1869, pág. 1912. Contestación de Augusto Ulloa al discurso del Marqués de Albaida de cuatro horas.

67 ULLOA, DSCC III, 73, 13 de mayo, pág. 1916.

68 GIL BERGES, DSCC III, 75, 17 de mayo, pág. 2017. «No negaréis que doña Isabel II tenía participación en el Poder Legislativo por la sanción de las leyes; pues por un artículo de vuestra Constitución, el incógnito monarca que habréis de traernos tendrá participación en el Poder Legislativo por la sanción de las leyes. Por todas las Constituciones que se han hecho en España durante el reinado de doña Isabel tenía el mando de las fuerzas de mar y tierra; pues el monarca $x$ que vais a traernos, tendrá el mando de mar y tierra, por vuestro proyecto de Constitución. Doña Isabel II sino fuera por el obstáculo que vosotros y nosotros la hemos puesto, podria transmitir por derecho de herencia, por derecho de sucesión, la Corona 
embargo, y a diferencia de nuestros anteriores textos constitucionales que atribuian la potestad de hacer las leyes a las Cortes con el Rey, el artículo 34 de la Constitución de 1869 introduce una nueva fórmula al prescribir que "la potestad de hacer las leyes reside en las Cortes. El Rey sanciona y promulga las leyes". De otra parte, muchas de las facultades otorgadas al monarca y que eran objeto de la crítica republicana, eran prerrogativas con las que también contaba la jefatura de Estado republicana, con más autonomía si cabe en las repúblicas presidencialistas. Además, mientras que en la Monarquía moderada el Senado era de nombramiento real, es decir, uno de los cuerpos deliberantes los nombraba el monarca, con lo que intervenía el monarca en la formación de las leyes, no solamente con la sanción, sino con el nombramiento íntegro de uno de los cuerpos deliberantes, por el contrario, en la Monarquía democrática de 1869, los dos Cuerpos deliberantes van a ser nombrados por sufragio universal, exigiéndose, además, que los ministros trajesen una investidura popular, con lo que nos encontramos ante un rasgo inequívoco del régimen parlamentario.

Curiosamente, durante el curso del debate constitucional, se emplearía el término de Monarquía parlamentaria, aunque, eso si, dándole un significado inapropiado al tratar de diferenciarlo del concepto de Monarquía popular. Será uno de los miembros de la Comisión Constitucional, don Eugenio Montero Ríos, el autor de dicha confusión, al identificar la Monarquía parlamentaria con la Monarquía moderada tradicional. Para éste mientras que la Monarquía popular se apoya en la base de la soberanía del pueblo, la Monarquía parlamentaría descansa en la legitimidad de la historia ${ }^{69}$. También los republicanos utilizaban de forma inapropiada el término de Monarquía parlamentaria al identificarlo con el concepto de Monarquía constitucional defendi-

bación, al juzgar por lo que entraña el proyecto que se discute. Derecho de gracia a su hijo. Exactamente lo mismo que podrá hacer ese monarca in yerba, en incutenía doña Isabel, el derecho de gracia a indultar a los criminales, derecho de gracia va a tener vuestro monarca $x "$.

69 El autor de este error es MONTERo Rios en contestación a Gil Berges, DSCC IV, 76, 18 de mayo, pág. 2024-2030. "(...) El señor Gil y Berges (...) combatía la Monarquía tradicional que busca la causa de su legitimidad en la historia; combatía si queréis la Monarquía parlamentaria, que es el producto de la lucha viva del derecho moderno con las antiguas ideas Monarquía de carácter transitorio, Monarquía que ha pasado al eterno panteón de la historia con sus glorias y con sus faltas; pero no combatía la Monarquía democrática que busca su fundamento, su razón de ser y su legitimidad en la soberanía del pueblon. 
do por Cánovas del Castillo, a la que se llega incluso a calificar de Monarquía reaccionaria ${ }^{70}$.

\section{REPÚBLICA FEDERAL VERSUS REPÚBLICA UNITARIA}

Entre la minoría republicana presente en las Constituyentes de 1869 triunfará la formula más radical de República, la federal, frente a la unitaria, únicamente defendida por los Diputados García Ruiz y Sánchez Ruano, a la que también en algún momento del debate constituyente se la denominó República conservadora.

En la defensa de la idea republicano federal participaría activamente el gran teórico del federalismo español, don Francisco Pi y Margall, quien guardaba evidentes concomitancias doctrinales con el anarquismo de Proudhon a quien había conocido durante su destierro en París, y de quien había traducido "Du Príncipe fédératif». Junto a éste, Estanislao Figueras y Moragas, y Emilio Castelar y Ripoll, Nicolás Salmerón no llegó a obtener acta de diputado en las Cortes Constituyentes de 1869, participando por primera vez en la vida política del Sexenio en las Cortes de $1871^{71}$. También se unirían a estos otras figuras relevantes del republicanismo español como eran Federico Rubio, el Marqués de Albaida, Adolfo de la Rosa, Juan José Hidalgo, Fernando Garrido uno de los primeros propagandistas del socialismo en España, o incluso futuros ministrables como Juan Tutau, José Cristóbal Sorní y Grau, y Chao.

De esta manera, el 12 de mayo de 1869 la minoría republicana presentaba en el Congreso de los Diputados una enmienda al artículo $33 \mathrm{del}$ proyecto constitucional que tenía como ponentes a Orense, Castelar, Figueras, Tutau, Chao, Garrido y Paul con el siguiente texto: «la forma de gobierno de la Nación española es la República democrático federal» ${ }^{72}$. Como recordaría el Marqués de Albaida, ya en 1854 él junto a otros diecinueve diputados, entre ellos, el Presidente de las Cor-

70 Es el caso de Abarzuza quien decía que la Monarquía democrática era non nata porque no existía en ninguna parte. DSCC III, 74, 14 de mayo, pág. 19556. "Aquí no hay más que dos caminos: o la bandera que ha levantado el Señor Cánovas, o la nuestra; o la Monarquía constitucional, la Monarquía parlamentaria, la Monarquía reaccionaria, o la República».

71 Si obtiene acta de diputado por Almería en las Constituyentes de 1869 su hermano don Francisco Salmerón que era progresista.

72 DSCC III, 72, 12 de mayo de 1869, pág. 1886. 
tes Constituyentes, Nicolás Maria Rivero, habian votado contra la Monarquía y su titular Isabel II73. Finalmente la enmienda sería rechazada por 182 votos contra 64. Como señala el profesor Peña González, estamos en el inicio de la gran polémica Monarquía-República, cuyo espíritu sería recuperado cincuenta años más tarde, entre otros por Manuel Azaña en su conocida "Apelación a la República" o en el discurso conmemorativo del aniversario de la I República celebrado el 11 de febrero de 1930, en un acto público patrocinado por Alianza Republicana ${ }^{74}$.

Como ya apuntábamos, a juicio de éstos sólo la República era la única forma de gobierno compatible con la soberanía nacional. La soberania del pueblo era incompatible con un poder irresponsable, inviolable $y$ hereditario como era el del monarca. Para estos la forma era inseparable de la esencia y, por tanto, sólo la forma de gobierno republicana era la única compatible con el dogma de la soberanía nacional, porque sólo en la República los poderes eran delegados, temporales y responsables. En este sentido, existe una enmienda de don Fernando Garrido que sería rechazada tras su segunda lectura por 157 votos contra 64 .

Curiosamente en 1869 las críticas a la República federal serian objeciones al modelo federal más que a la forma de gobierno republicana. Se olvidó que el Estado federal no es más que una técnica de distribución territorial del poder político, es, como escribiera Friedrich, la forma territorial de la división de poderes, y que la fórmula federal era igualmente válida tanto para la Monarquía como para la Repúbli-

73 Ya en el mitin del Circo Price, celebrado el 1 de octubre, después de que oyera algunos aplausos cuando describia las instituciones de Suiza, terminó su discurso diciendo: «En resumen, señores, la forma de gobierno que adopta la democracia española ¿es la República federal o la unitaria...?". Calló el concurso porque, entre otros motivos, muy pocos sabía allí lo que eran federación y unitarismo; pero una voz gritó desde la galería: "federal"; y como Martos se manifestase molesto por aquella salida de tono, otras cuantas voces repitieron la misma palabra, con lo que Orense, sin pararse en más, dijo: "Queda acordado que la República federal es la forma de gobierno que adopta la democracia española». Con esa ligereza y alegre ignorancia se decidió por la República federal y no por la unitaria, la multitud congregada en el circo Price, si bien se produjera la irreparable escisión de Rivero y Martos". Fernández Almagro, op. cit., págs. 27-8.

Los Diputados que en 1854 votaron contra la Monarquía de Isabel II fueron Ruiz Pons, Lozano, Alfonso Surís, Chao, Sorní, Clavet, don Fernando Mádoz, Bertemati, don Alonso Navarro, García Ruiz, García López, Marugán, Rivero, Ferrer y Garcés, Orense, Pereira, Figueras, Ordax y Avecilla.

74 Peña GonzAlez, J., Cultura Política y Constitución de 1869, CEPC, 2002. 
ca. Sólo algunos Diputados como Romero Girón o Sagasta tuvieron una clara visión de esto durante la discusión parlamentaria ${ }^{75}$. También la minoría republicana federal, como ya hicieran los defensores de la Monarquía democrática al ligar su origen a las antiguas Monarquías castellana y aragonesa, tratará de encontrar antecedentes de la forma federal en el sistema político de la antigua Monarquía aragonesa, en la que existió una federación de cuatro reinos independientes. Nuevamente y como será lo habitual en el debate se tratará de justificar la existencia de un Estado federal más que argumentar a favor de la forma de gobierno republicana ${ }^{76}$.

A lo largo de todo el debate, como no podía ser de otra forma, van a ser constantes las referencias de los constituyentes a los Estados Unidos y Suiza. Los republicanos federales de 1869 fueron por lo general acérrimos defensores del modelo norteamericano, no obstante, a diferencia de su modelo ideal se mostraron abiertamente partidarios de un sistema unicameral, aunque finalmente en el proyecto constitucional de 1873 optarían por un legislativo bicameral. En el debate de las Constituyentes de 1869, los republicanos federales nunca fueron partidarios de la existencia de una segunda Cámara, porque a su entender la división del legislativo en dos Cámaras atentaba contra la soberanía nacional, sin reparar en que la existencia de una segunda Cámara en los Estados compuestos obedecía a la necesidad de representar a las distintas entidades terri-

75 DSCC, IV , 78, 20 de mayo de 1869, pág. 21. Para Romero Girón, ula federación cabe dentro de la Monarquía como de la República. Será más perfecta y compieta en la República pero no repele a la Monarquía (...) desde la liga anfitriónica de Grecia, hasta las últimas confederaciones de los Estados monárquicos, ora el de Hannover con Inglaterra, ora el de Inglaterra con Irlanda y Escocia, ora por último el de Austrian.

DSCC, IV, 93, 7 de junio de 1869, pág. 2584. Para Sagasta, «lo mismo pueden ser federales entre si las naciones con presidentes que con monarcas a la cabezan.

76 Sorni, DSCC IV, 76, 18 de mayo de 1869, pág. 2036. "Se decía días pasados que en este país la forma federal no tenía tradición. (...) En Aragón, señores, a diferencia de lo que sucedia en Castilla se realizó siempre una federación de cuatro reinos. Cuando por el matrimonio del Conde Berenguer con la Reina Petronila se unió la Corona de Aragón con el condado de Barcelona, no se confundieron los dos reinos sino que conservaron sus instituciones propias, instituciones distintas, las instituciones democráticas que cada uno de ellos tenía. Cuando el Rey Don Jaime conquistó Valencia tampoco incorporó aquel reino a la Corona de Aragón ni a la de Cataluña sino que lo constituyó en reino independiente. (...) Cuando conquistó a Mallorca también estableció allí otro reino independiente". 
toriales que lo conforman77. Curiosamente, la Constitución de 1869 establecerá un Senado en el que se pueden apreciar claramente las influencias del Senado norteamericano, que ya serian resaltadas en el debate constituyente por algunos Diputados como Moret, Salmerón o Gil Sanz ${ }^{78}$.

Frente al grupo mayoritario de diputados que mostraba sus preferencias por el modelo norteamericano, y por tanto, por un modelo de República presidencialista, otros apostaron por una República de corte asambleario, más propia del constitucionalismo francés de la época más revolucionaria, de ese "Rousseau sin adulterar y sin mezcla, archidemocrático, archirrepublicano y monolítico hasta el final» 79 . De entre estos destaca Paul y Angulo quien en la enmienda ya citada a los artículos 32 y 33 del proyecto constitucional propuso la creación de un Directorio de cinco individuos nombrados por las Cortes cada tres años, el cual parece guardar ciertas semejanzas con el modelo suizo de 1848, a su vez influenciado por el Directorio de la Constitución francesa de 1795, no obstante el número se reduce de 7 a 5 miembros, y la designación se hace cada tres años, a diferencia de los cuatro años previstos en el caso suizo. También durante el debate constitucional aparecieron algunas otras propuestas favorables al establecimiento de un gobierno de asamblea que hacía recordar al sistema de gobierno establecido por la Convención francesa en su Constitución de 24 de junio de 1793. Fue el Marqués de Albaida, don José María Orense quien propondría un sistema de gobierno en que la Asamblea legislativa tuviera un dominio absoluto sobre el Ejecutivo, que por otra parte no tenía por que ser colegiado. La Asamblea tenía el poder para designarlo, pero también, para destituirlo, las diferencias con el modelo suizo eran notables, pues, en éste, la separación de poderes era más

77 DSCC, IV , 76, 18 de mayo, 2027. Ello fue criticado por el Diputado Montero Ríos quien se manifestaba en los siguientes términos: "Pero señores ¿ataca la organización del Poder legislativo compuesto de dos Cámaras a la soberanía popular, a la idea democrática? (...) Los señores de enfrente, que tienen su bello ideal en la República norteamericana y que proclaman la República federal, que no se concibe sin la organización del Poder Legislativo en dos Cámaras, violan también esa misma soberanía».

78 ROMERO GiRón afirmaría que «es el Senado que nace del reconocimiento dentro de ese Estado general de la Nación española de otros Estados secundarios pero que tienen su personalidad politica y administrativa. A esto responde el pensamiento del Senado, a establecer para el porvenir los fundamentos políticos de la federación". DSCC, IV, 78, 20 de mayo de 1869, pág. 2111.

79 K. Loewenstein, Teoría de la Constitución, Barcelona, 1970, pág. 99. 
rígida, y el Parlamento no podía hacer dimitir al Consejo que, además, es siempre colegiado ${ }^{80}$.

No sólo la mayoría gubernamental, sino incluso también los republicanos unitarios censuraron la llamada República disolvente o descoyuntada 81 , al considerar que el Estado federal norteamericano y suizo, eran modelos foráneos que se habian formado obedeciendo a circunstancias históricas particulares y concretas que no podían ser trasladables al caso español. Para estos, el Estado federal sólo tenía sentido cuando se trataba de la integración de unidades autónomas en una unidad superior, y no para desintegrar un Estado ya constituido como era el caso de España. Para los defensores del proyecto constitucional, la formación del Estado federal en estos dos países se debía a un largo proceso histórico de cientos de años, durante los cuales se había ido produciendo la vinculación de los diferentes entes territoriales, ya fueran los Estados o cantones, primero a través de la confederación hasta llegar finalmente a la constitución más compleja de la federación. El caso de España era, por tanto, radicalmente diferente, puesto que se trataba de un Estado unitario que para su conversión en Estado federal, necesitaba de un acto previo de desintegración jurídica, para que pudiera darse con posterioridad esa unión federal ${ }^{82}$. No

80 DSCC III, 75, 17 de mayo de 1869, pág. 2002. Refuerza esta teoría el hecho de que Orense en el programa que presentó en Valencia el 29 de Octubre de 1869 defendió la existencia de una Asamblea única, elegida anualmente por sufragio universal directo $y$ un presidente del ejecutivo nombrado por la Asamblea sin tiempo limitado y amovible a voluntad de la misma Asamblea. Sin embargo, Orense en el mismo debate constituyente en algunos momentos defendería el modelo norteamericano de fuerte ejecutivo cuando en respuesta a Silvela decía "no queremos la anarquía, porque en el momento en que se establezca un gobierno como el de los Estados Unidos, no es posible la anarquía. (...) Una institución tan fuerte como es el Poder ejecutivo en los Estado Unidos, es muy bastante para conservar la coexión nacional; para lo que no es bastante en ningún caso es para tiranizar al pueblo»; mientras que en otros defendió un gobierno de Asamblea: el Ministro de la Gobernación recoge unas palabras de Orense a favor del gobierno Asambleario: "Yo no quiero ni Rey ni Roque, porque los presidentes han dado malos resultados así en el año 48 en Francia como ahora en los Estados Unidos; por eso quiero una República sin presidentes: una República en el que el presidente sea la Asamblea». DSCC, IV, 94, 8 de junio de 1869, pág. 2605. También durante el debate constituyente se mostró partidario del modelo suizo. DSCC, IV, 77, 19 de mayo de 1869, pág. 2088.

81 El término de disolvente fue empleado por GIL SANZ, DSCC II, 42, 6 de abril de 1869, pág. 863. También BECERRA emplearía el calificativo de descoyuntada, DSCC II, 48, 13 de abril de 1869, pág. 1014.

82 DSCC III, 73, 13 de mayo de 1869, pág. 1916. Así, UlLoA se preguntaba: "¿Cómo, Señores, vamos nosotros a rasgar toda nuestra historia?, ¿cómo vamos 
obstante, y a pesar de las críticas convine señalar que tal vez esta fórmula federal hubiera sido la técnica más adecuada para articular los restos de un imperio colonial que todavía se conservaban.

Uno de los argumentos más interesantes que se introducirán en el debate parlamentario será el formulado el Diputado don Gabriel Rodríguez, quien señalaba como antecedente del federalismo español el sistema de juntas que se formaron en los días inmediatamente anteriores a la Revolución de Septiembre ${ }^{83}$. También $\mathrm{Pi}$ y Margall vio en el fenómeno de las juntas el antecedente más claro del federalismo español pero su origen lo remonta a la época de ocupación francesa ${ }^{84}$.

a esterilizar los esfuerzos de tantos siglos, de tantas generaciones, y a destruir en un solo día la obra verdaderamente titánica de nuestros mayores? ¿Y todo para qué? ¿Para modelarnos por los cantones suizos? (...) Dentro de cincuenta años el interior de España no sería más que un basto aduar de beduinos».

DSCC IV, 76, 18 de mayo de 1869, pág. 2046-7. De la misma manera, Gabriel RODRIGUEZ: «En mi concepto la República federal es la unión, la asociación de varios Estados que existen previamente, formando cada uno de ellos una unidad política especial. En la historia, (...) vemos que todas las Repúblicas federales del mundo se han creado preexistiendo ciertos Estados, con unidad política independiente, con condiciones diversas de derecho, con condiciones económicas y sociales distintas. Estos Estados preexistentes para sostenerse y defenderse mutuamente, para objetos que en común les interesaban, se fueron asociando y confederando. Así se ha formado Suiza, y los Estados Unidos. Así han nacido las Repúblicas federales que se conocen en el mundo. Pero en un Estado unificado ya (...) hacer de repente una República federal, esto no ha sucedido nuncan.

DSCC IV, 93, 7 de junio de 1869, pág. 2584, Así el Ministro de la Gobernación (Sagasta): "Aunque se haya hablado de la República federal universal, no se ha ocurrido a nadie hacer una República federal de una Nación, despedazando su historia, su grandeza, sus recuerdos, sus tradiciones. Cuando se ha hablado de la República federal universal se ha aludido a la República federal de las diversas naciones que por raza, por tradición o por cualquier otra causa debieran unirse para las cuestiones del porvenir (...)"n.

83 DSCC IV, 76, 18 de mayo, pág. 2046. Gabriel RodríguEZ se expresa en los siguientes términos: "Sólo habría un medio, Señores diputados de plantear la República federal en España (...) y consiste en retrotraer la situación dél país a los días inmediatos a la Revolución de Septiembre, hacer que todas aquellas Juntas que entregaron el poder al gobierno central vuelvan a constituirse y diciéndoles: "sois soberanas, sois independientes, asociaos y confederaos si queréis" este es el único procedimiento para tener en España una República federal, desorganizar el país, dividirlo, pulverizarlo, por decirlo así, no dejando vivo ninguno de los actuales elementos políticos de España».

84 DSCC IV, 77, 19 de mayo, pág. 2095, PI Y MARGALL: «Cuando todas esas provincias están apegadas aún a su lengua, a sus costumbres, a los fueros que aún conservan; cuando aún recuerdan con fruición los fueros que tuvieron y han perdido, me venís diciendo que existe la unidad y que es preciso conservarla (...) pre- 
Como dice Carr upara los republicanos federales posteriores la España de la Guerra de la Independencia había sido ya una República Federal gobernada por los conservadores" 85 .

Ciertamente el fenómeno del juntismo no era nuevo en España, pues desde 1808 las juntas siempre habían aparecido en los momentos de vacío de poder en la vida política española. En 1868 el papel de las juntas volvería a ser decisivo. Durante 1867 existieron varias Juntas como las de Barcelona, Córdoba, Zaragoza y Madrid que preparaban el camino para el levantamiento revolucionario del año siguiente. Desde el primer momento fueron frecuentes los roces entre las juntas locales y provinciales. Así, las Juntas de Carrión, Calahorra, Tortosa y Puerto de Santa María no aceptaron subordinación alguna a la Junta de la capital. El reparto de tierras en Ubrique y Arcos apoyados por las juntas locales fueron anulados por la Junta gaditana provincial. También las Juntas de Denia, Alcoy y Orihuela entraron en conflicto con la Junta Provincial de Alicante. De la misma manera, la Junta de Santiago entró en conflicto con la de La Coruña por razones de supremacía. Algunas juntas pensaron en crear una Junta Central a imagen y semejanza de la creada durante la guerra de independencia. Con tal motivo, las Juntas de Valladolid, Soria, Teruel y Huesca enviaron dos representantes a Madrid. La Junta de Almería propuso la creación de ésta con representación de todas las provincias. Sin embargo, sería la Junta Revolucionaria de Madrid ${ }^{86}$ la que asumiría desde el primer

cisamente ese espiritu provincial, ese espiritu foral que existe en las provincias hace que tenga una gran fuerza siempre que sobreviene en España una gran crisis. Vino por ejemplo el año 1808 (...) pero precisamente porque existía ese espíritu provincial en todas partes, las provincias se constituyeron independientemente de Madrid, formaron Juntas, hicieron armamentos, levantaron a los pueblos (...) es una forma federạl que busca la unidad como la presenta la naturaleza, es decir, en la variedad, no la unidad en la uniformidad".

85 CARR, R., Historia de España 1808-1975, págs. 100, 136-7 y 168.

86 El 29 de septiembre de 1868 se formó la Junta Provisional Revolucionaria en el Ayuntamiento presidida por Nicolás María Rivero y compuesta por miembros de los partidos progresista, unionista y demócrata. Junto a esta, se encontraba la Junta presidida por Escalante en el Ministerio de la Gobernación. Ambas juntas se fusionaron formando la Junta revolucionaria de Madrid compuesta de 40 miembros entre los que se encontraban: Pascual Madoz, Nicolás Maria Rivero, Lorenzana, Estanislao Figueras, Laureano Figuerola, el Marqués de la Vega de Armijo, José Cristóbal Sorní, Romero Robledo, Olózaga, Rojo Arias, Eduardo Chao, Ortiz de Pinedo, Adolfo Joaritzi, Carratalá, y José María Orense. La Junta se ocupó de la seguridad interior (custodia del Banco de España, Casa de la Moneda y Casa de Depósitos), repartió armas, organizó a los Voluntarios de la Libertad y 
momento la soberanía nacional tras la marcha de la Reina, y será la Junta de Madrid la que encomiende al General Serrano el 4 de octubre de 1868 la formación de un Gobierno Provisional "que se encargue de la gobernación del Estado hasta la reunión de las Cortes Constituyentes" $y$, además, se compromete a que el Gobierno Provisional sea "la más genuina y directa personificación de una revolución que aspira a levantar, por medio del ejercicio de la soberanía nacional, el edificio permanente $e$ incontrastable de las públicas libertades». Es decir, durante varias semanas coexistirian dentro del país dos poderes, uno el del Gobierno provisional y el otro el de las juntas, situación que se agravaría en aquellos lugares donde las juntas se negaron a disolverse, en este sentido, conviene recordar que las Juntas de Barcelona, Huesca, Teruel y Valencia protestaron ante la Junta Suprema de Madrid por haberse arrogado la representación nacional y haber nombrado al General Serrano jefe del Gobierno Provisional. La tarea básica del Gobierno provisional, consistiría, pues, en sustituir esta dualidad de poderes que se había creado. En el decreto del Gobierno de 20 de octubre de extinción de las juntas se adujeron razones históricas como la de ser desde 1808 a 1854 instituciones transitorias que cedieron el paso a gobiernos legítimos; y razones prácticas, como las dificultades que ocasionarian al Gobierno su subsistencia.

El movimiento juntero volvería a renacer en 1869 pero ahora controlado por el partido republicano. Es digno de mención el hecho de que mientras se está debatiendo en las Cortes Constituyentes la forma de gobierno, van a tener lugar los llamados pactos federales de Tortosa de 18 de mayo de 1869 promovido por Valentín Almirall, y redactado por los comités de Cataluña, Aragón, País Valenciano, y Baleares, "Pacto de la Coronilla de Aragón". Posteriormente tendrían lugar los Pactos de Córdoba, Valladolid, La Coruña, Éibar y Madrid de 30 de junio de 1869. Inmediatamente después de la aprobación parlamentaria de la forma de gobierno monárquica, en septiembre

consiguió que el pronunciamiento se realizara en orden gracias a la actuación de Madoz, Ros de Olano y Rivero. El 5 de octubre se constituyó la Junta Superior Revolucionaria que desde el 12 de octubre se autotituló Superior de gobierno y se atribuyó la tutela del Gobierno Provisional. Finalmente se disolveria alegando que estaba asegurado el orden público; que era el Gobierno Provisional a quien le incumbia la tarea de plantear los principios proclamados por la Revolución; porque dicho Gobierno, formado por los principales caudillos de la Revolución, era digno de la confianza de todos los liberales; porque la existencia de las juntas podía embarazar la marcha del Gobierno; y porque ya se había constituido el Ayuntamiento y la Diputación Provincial. Moliner, A., op. cit., págs. 304-7. 
de este mismo año se produce una sublevación federal en numerosas zonas del país en las que van a estar implicados algunos de los diputados constituyentes republicanos ${ }^{87}$. De lo expuesto hasta aqui, podemos decir que el fenómeno juntero superaba con mucho el fenómeno meramente federal, situándose en el ámbito más propio de la confederación desde el momento en que las distintas juntas provinciales no reconocían otra soberanía que no fuera la suya. De esta forma, el juntismo español se convertía en el antecedente más claro de ese radicalismo local que llevado a sus máximas consecuencias desembocaría en la sublevación cantonalista de 1873. Todo ello, sin olvidar que a lo largo de todo el debate constituyente será frecuente la confusión de los constituyentes en torno a los conceptos de federación - confederación, federalismo - confederalismo. Se empleaban indistintamente términos como Estado federal, federación, confederación y Nación confederada sin reparar en que se trataba de conceptos diferentes, con consecuencias jurídicas también distintas. Y la cuestión no era baladí, porque según se optara por uno u otro término se podía estar reconociendo, la soberanía del "todo", la soberanía del Estado español, o por el contrario, se reconocía únicamente la de "las partes", la soberanía de cada una de las regiones o provincias que lo integraban con las subsiguientes consecuencias jurídicas y políticas.

También una posible unión entre España y Portugal, la llamada unión ibérica, que había sido el argumento de Olózaga para patrocinar la candidatura de Fernando de Coburgo al Trono español, a través de la llamada "Monarquía diplomática», se plantea como argumento para favorecer el establecimiento de la forma de gobierno republicana. Los republicanos federales, también, serán defensores de la unión ibérica, pero a través de lo que para ellos es la única forma posible: la República Federal. Otros, incluso, como Castelar van más lejos de la simple unión ibérica, y llegan a patrocinar la idea de unos Estados Unidos de Europa, eso sí, de una Europa Latina que pudiera hacer frente

87 JUTGLAR dice que la sublevación federal fue el primero de los movimientos armados del Sexenio efectuados a partir de la iniciativa de las masas populares, sin contar todavía con los militares al revés de lo que ocurriría en 1873 con la sublevación cantonalista alimentada por militares diversos como el General Contreras, al igual que ocurrió antes con el de Pérez del Álamo en Loja, pocos años atrás, en que estuvieron sublevados igualmente a favor de la República democrática o federal social. Historia de España de MENÉnDEZ PELAYO, tomo XXXIV, "La Revolución de Septiembre, el Gobierno provisional y el reinado de Amadeo", pág. 682. 
a la autocracia militar de raza germánica que se estaba formando 88 . Curiosamente, años más tarde, tras la derrota francesa de Sedán, Cánovas hablaría de la hegemonía de los pueblos del Rhin.

La reprobación de la República federal, no sólo provendrían de los partidarios de la Monarquía, sino que también los republicanos unitarios mostrarian su oposición a la misma. Solamente dos Diputados Eugenio García Ruiz y Julián Sánchez Ruano defenderian la denominada República unitaria. García Ruiz propondría la siguiente enmienda al artículo 33 del proyecto constitucional: «la República Democrática es la forma de Gobierno que adopta la Nación española", que sería rechazada por 157 votos frente a dos. Sánchez Ruano por su parte presentó otra enmienda al citado artículo en los siguientes términos: "la forma de gobierno de la Nación española es la República» ${ }^{89}$. El principal reproche de los republicanos unitarios a los republicanos federales se centró en la técnica de distribución territorial del poder propuesta por estos últimos. García Ruiz se quejaba de la falta de concreción de los federalistas a la hora de definir quienes iban a ser los componentes de la federación, no se especificaba si lo serían las regiones, las provincias o incluso los municipios, lo cual resultaba problemático teniendo en cuenta los acontecimientos histórico-políticos acaecidos en nuestra Nación como consecuencia del fenómeno del juntismo, cuando juntas como la de Cartagena se habian declarado soberanas $^{90}$. Éste se mostraba partidario de una República unitaria

88 DSCC IV, 78, 20 de mayo, págs. 2116 y 2126, CASTELAR se expresa en los siguientes términos: "¿Queréis los Estados Unidos de Europa? (...) Yo había soñado que con la Revolución de Septiembre podria alcanzarse que España, mi patria, fuese el primer país que fundara los Estados Unidos de Europa. (...) la Nación española sabe muy bien que sólo por la República puede cumplir sus destinos en Europa porque Europa tiene miedo a una confederación, confederación paneslavista que ha tomado el centro de Europa, Polonia; que ha tomado en Oriente Crimea, $y$ la Europa tiene miedo a una autocracia militar que se está formando en la raza germánica tal vez contra la raza latina. Y contra todos esos grandes peligros no hay más que un medio: la confederación de la raza latina, la confederación de la Europa latina, y la confederación de la península ibérican.

89 DSCC III, 7313 de mayo, págs. 1922 y 1929.

90 DSCC III, 7313 de mayo, págs. 1924-5. En este sentido, GARCla Ruiz manifiesta lo siguiente: "¿Cuántas Repúblicas o Estados habría con ese sistema de federación? Unos contestan que catorce como los antiguos reinos; otros tantos como provincias que son cuarenta y nueve. $Y$ yo digo que habría más de mil, fundado en lo que todos hemos visto en esta revolución respecto a las juntas de gobierno: pueblos pequeños declarándose independientes sin reconocer a la cabeza de partido, ni ésta a la capital de provincia. (...) La proclamación de la República federal 
descentralizada administrativa y políticamente a nivel provincial, aunque no entraba en definiciones ${ }^{91}$. La República unitaria sería censurada tanto por el lado de los republicanos federales como por el bando monárquico. El argumento iba a ser el mismo para ambos: la República unitaria conduce a la dictadura ${ }^{92}$. Curiosamente, y siendo los republicanos españoles en su mayoría, al menos en teoría, tributarios del modelo norteamericano, su censura se dirige hacia las Repúblicas de carácter presidencialista a las que identifican con Repúblicas de corte autoritario. Nuevamente nos volvemos ha encontrar ante una clara imprecisión técnica, dado que el adjetivo unitaria hacía referencia a la forma de organización territorial del poder, pero en ningún caso se refería a la forma de gobierno. El otro de los defensores de la República unitaria, el Diputado Sánchez Ruano, utilizará la expresión República conservadora, a la que va a definir como la forma de gobierno que hace posible la conciliación del orden con la libertad, y el respeto de los derechos individuales ${ }^{93}$. La crítica a la República conservadora

en España sería hoy aquí la señal de la más espantosa anarquía y lo mejor que podríamos apetecer es ir a parar a un despotismo (...) el día de la manifestación republicana (...) vi una bandera que decía "República federal de Novelda". ¿Es decir, que cada calle de Novelda forma un pequeño Estadito y juntos todos forman la República federal de Novelda? Creen que la República federal es que el alcalde del último pueblo de España se pueda constituir en Presidente de una República. (...) Nosotros votamos en el año 54 la República a secas, sin hablar nada de federal».

91 DSCC III, 73, 13 de mayo, pág. 1926. «No hay, pues, otra República posible que la democrática unitaria, eminentemente decentralizadora; porque yo la quiero con diputaciones casi independientes para lo administrativo, casi independientes para lo político, que tengan vínculo de unidad con lo que se llama nacionalidad, porque quiero que de esa manera no concluya con lo que se llama patria comúnn.

92 DSCC II, 44, 8 de abril, pág. 919. En este sentido se pronuncia MORET Y PRENDERGAST: « las Repúblicas unitarias esas no son Repúblicas, esas no son más que el gobierno de un Presidente ungido, no con el óleo de los Reyes sino con el óleo de los deseos y las exigencias de las muchedumbres. En las Repúblicas unitarias o el Presidente es nombrado por las clases conservadoras para sostener la República en un momento, como ha sucedido en Francia con el elegido en diciembre, o el Presidente es una dictadura militar, como lo fue en la I República francesa durante sus últimos años, o por último el Presidente es jefe de una República socialista como la de Paraguay".

93 DSCC II, 42, 6 de abril, pág. 859. "(...) Aquí no hay nada posible, que no hay nada serio, que aquí no hay nada con condiciones de duración $y$ estabilidad más que una República, y una República conservadora. Conservadora porque representaría todos los intereses de la justicia, todos los derechos individuales, el porvenir, no sólo de esta generación, sino de todas las generaciones, el porvenir no solamente de España, sino quizá de toda Europa; República conservadora que predica no lo que vosotros decís, quizá sabiendo que no es verdad, no el desor- 
fue hecha por Becerra, al identificarla con una forma de gobierno no democrática94.

Durante el debate serán constantes las solicitudes presentadas por los diferentes diputados republicanos a favor de la República de distintos ayuntamientos, vecinos, comités republicanos etc., tratando de alguna manera de influir sobre la Cámara. Estos van a proponer en su mayoria la República federal, aunque en ocasiones no se especifica y se refieren únicamente a la República democrática ${ }^{95}$.

Finalmente, y después de ocho días de una apasionada discusión, más lenta y fatigosa de lo que era deseable para el país, el artículo 32 sería aprobado por unanimidad, mientras que el art. 33 que

den, no el pillaje, no el reparto, sino el orden la libertad, la tolerancia, el respeto a los demás. República conservadora que predica la paz, no la guerra, que predica no la muerte y la sangre, sino la abolición de la pena de muerte para todos; que no predica el derramamiento de sangre, que no tanto perjudica a las víctimas como mancha al verdugo".

94 DSCC II, 48, 13 de abril, pág. 1012. "(..) Por lo demás, República conservadora o es un nombre más, o si no lo es, será una República con leyes conservadoras, y como el nombre no hace a las cosas, llámese República, llámese Monarquía será conservadora, no democrática». DS 13 de abril de 1869, tomo II, pág. 1012.

95 Solicitudes expresadas por: Sr. Llorens, una de varios vecinos de Colmenar de Oreja, solicitando que se proclame la República federal como forma de gobierno. Sr. Blanc, una de varios vecinos de la villa de Sabiate y el Ayuntamiento y Comité republicano de Barbastro, pidiendo la República como forma de gobierno. Sr. Orense, una del Comité republicano de Astillero, de Guarnizo, de Daimiel, de la villa de Novelda, y de Ciudad Real, pidiendo que se proclame la República como forma de gobierno. Sr. Suñer y Capdevilla una de varios vecinos de Palau Sator y de los republicanos federales de Labisbal solicitando la proclamación de la República federal. Sr. Pi y Margall una de varios vecinos de Almería y de varios pueblos de la provincia y los vecinos y el Club Republicano de Quintanar de la Orden solicitando la proclamación de la República democrática. Sr. Castelar del ayuntamiento de Valladolid y ciudadanos de Albarique de Masalaves, de Almansa, de Daimiel, de Pozuelo, y Villarrubia de los Ojos pidiendo que se proclame la República democrática federal. Sr. Ruiz y Ruiz de varios vecinos de Máchale para que se establezca la forma republicana. Sr. Figueras de ciudadanos de Mataró para que se proclame como forma de gobierno la República democrática federal. Sr. Soler por el Comité republicano de Zaragoza y vecinos de Purroy, Illueca, Calatayud, Inojes, Osera, y Mesones para que se declare la República democrática federal. Sr. García Ruiz por el Comité Republicano de Granada proclamando como forma de gobierno la República democrática. Sr. Fantony por el Comité republicano de Cabezas de San Juan por la República democrática federal. Sr. Pierrand por el Comité republicano de Santa Lena pidiendo la República democrática. DSCC III, 74, 14 de mayo, pág. 1964. 
reconocía a la Monarquía como la forma de gobierno de la Nación española sería aprobado en votación nominal por 214 votos contra 71 , eran las doce y media del día 21 de mayo, poniéndose fin a un debate iniciado el día 12 de mayo y para el que se habilitaron sesiones de mañana, tarde y noche. De esta manera, las Constituyentes de 1869 aprobaban la Monarquía como forma de gobierno aunque faltaba en ellas una verdadera convicción monárquica ${ }^{96}$, y es que como dice Sánchez Agesta97, la caída de la Reina quebró los pilares de una autoridad tradicional y en altos y bajos arruinó el respeto de una institución secular, que no podia rescatar fácilmente una nueva dinastía ${ }^{98}$.

96 El sentimiento republicano estaba presente en muchos de los diputados que habían votado a favor de la Monarquía. Como ejemplo baste una carta escrita por el Presidente del Congreso de los Diputados Nicolás María Rivero en los primeros momentos de la Revolución, y que sería publicada en el diario La Época el 23 de febrero de 1869 en la que se decía entre otras cosas lo siguiente: "(...) Yo soy y seré republicano, y si en los momentos presentes he proclamado la Monarquía es por la convicción íntima que tengo de que sólo con esta forma de gobierno puede ser fecunda la Revolución de Septiembre. Observe usted que esta grandiosa obre ha sido producto de los esfuerzos de tres partidos, dos de los cuales no son republicanos ni democráticos; en esta situación yo he preferido transigir con la Monarquia, con tal de atraer a la democracia a esos mismos partidos e interesarlos en consolidar la grande obra revolucionaria. (...) Asegurados hoy los principios democráticos la República no esta más que aplazada».

97 SÁnCHEZ Agesta, L., op. cit., pág. 261.

98 DSCC IV , 76, 20 de mayo, págs. 2145-6 y 7.

Se aprueba el artículo 33 por 214 votos contra 71. Señores que dijeron sí: Llano y Persí, Carratala, Serrano, Prim, Topete, D. Práxedes Mateo Sagasta, Romero Ortiz, Álvarez Lorenzana, Figueras, Ruiz Zorrilla, López de Ayala, Cantero, Posada Herrera, Rubin, Gasset y Artime, Serrano Bedoya, López Domínguez, Otero y Rosillo, Rubio Caparrós, Vidal y Villanueva, Madoz, don José Alcalá-Zamora, Salmerón, Ruiz Capdepón, Peset, don Mariano Ballesteros, Rojo Arias, don Juan Ulloa, O'Donnell, Damato, Izquierdo, Santonja, D. José Vicente Rivero, Milans del Boch, Bueno y Gómez, Salazar y Mazarredo, Mata, D. Cirilo Álvarez, Olózoga, D. Augusto Ulloa, Valera, D. Venancio González, D. Luis Alcalá Zamora, Silvela, Montero Ríos, Pérez Zamora, Montero Telinge, Baldrich, Álvarez Sotomayor, Romero Robledo, Rodríguez Leal, Álvarez Borbolla, Navarro, Suárez Inclán, Herrera, Dávila, Ruiz Gómez, Moret, Muñoz Bueno, Herreros de Tejada, Balaguer, Capdepón, López Botas, Arquiaga, Matos, Rodríguez Seoane, Gil Vírseda, Rodríguez Pinilla, Palau y Coll, Carrillo, Toscano, Cisneros, Marqués de la Vega de Armijo, Villalobos, CabaIlero de Rodas, Moreno Benítez, Núñez de Arce, Monteverde, Palau de Mesa, Delgado, Herrero, Fesratges, Jover, Calderón Collantes, Merelles, Mosquera, Muñiz, Gil Sanz, Marqués de Camposagrado, Fernández Vallín, Duque de Tetuán, D. Leandro Rubio, Eraso, Santiago, Pérez Cantalapiedra, Macías Acosta, Oria, Vado, Moncasi, Gomis, Rius, Abascal, Maluquer, Navarro y Ochoteco, González Alegre, Villavicencio, Reig, D. Diego García, Madrazo, Ory, Aparicio Moreno, Fernández del Cueto, D. Jacinto Ballesteros, Bastida, Macías Castelo, Sánchez Guardamino, Para- 
dela, D. Gaspar Rodríguez, Soto, Barreriro, Vázquez Curiel, D. Vicente Rodríguez, De Blas, Montejo, Montero de Espinosa, curiel y Castro, Ardanaz, D. Eduardo León, Ruiz Zorrilla, García Briz, Igual y Cano, De Pedro, Cascajares, Fuente Alcázar, Santos, Marqués de Santa Cruz de Aguirre, Masa, Sancho, Ortiz de Pinedo, Pascual, Iranzo, Nieulant, D. Pedro Mateo Sagasta, Fontanals, Bueno, Pino, León y Medina, Argüelles, Moreno Nieto, Baeza, Sanz, D. Manuel Vicente García, Cancio Villamil, Saavedra, Franco Alonso, Conde de Encinas, Mesía y Elola, Santa Cruz, Lasala, Yánez Rivadeneira, García Gómez, Muñoz de Sepúlveda, Ruiz Vila, Jalón, Montesino, Ortiz y Casado, Gallego Díaz, Soroa, Bañon, García de Quesada, Dieguez Amoeiro, Contreras, Martínez y Ricart, Chacón, Toro y Moya, Carballo, D. Luis Estrada, Vázquez de Puga, Méndez Vigo, Elduayen, Álvarez Bugallal, Cánovas del Castillo, Alvareda, González Marrón, Ríos y Rosas, Herraiz, Jontoya, Marquina, Jimeno y Agius, Romero Girón, Uzuriaga, Carretero, Sánchez Borguella, Pellón y Rodríguez, Prieto, Echegaray, Coronel y Ortiz, D. Gabriel Rodriguez, Ramos Calderón, Moya, Becerra, Fernández de las Cuevas, Godinez de Paz, Anglada, Soriano, Jiménez de Molina, Martínez Pérez, Carrascón, Pastor y Huerta, Martos, Moliní, Morales Díaz, Merelo, Sr. Presidente. Sres. que dijeron no: Sánchez Ruano, Gil Berges, D. Juan Pablo Soler, Río y Ramos, Benavent, D. Fernando Garrido, Hidalgo, Díaz Quintero, Maisonnave, García Ruiz, Tutau, Cala, Salvany, Sorni, Guerrero, Prefumo, Castillo, Ruiz y Ruiz, Álvarez Acevedo, Fantoni, Pierrad, Joarizti, Noguero, Soler y Plá, Guzmán y Manrique, Jimeno, Ferrer y Garcés, Palau y Generés, Caymó, Ameller, Moreno Rodríguez, D. Federico Rubio, Pi y Margall, Llorens, Bori, Gastón, Robert, Chao, Rebullida, D. Adolfo de la Rosa, Santamaría, D. Ramón Castejón, Lardies, Caro, Carrasco, Paul y Picardo, D. Pedro Castejón, Villanueva, Castelar, Benot, Caballero, Bobé, García López Moxó, Alsina, Pruneda, Sánchez Yago, Serraclara, Compte, Albors, Abarzuza, Pastor y Landero, Guillén, Orense, Figueras, Palanca, Blanc, Paul y Angulo, D. Gumersindo la Rosa, D. Enrique Guzmán, Suñer y Capdevila. (DSCC 20 de mayo de 1869 , tomo IV, $n .^{\circ} 78$, págs. 2145-6-7).

Al día siguiente votaron sí: Calderón y Herce, Aguirre, Alarcón, D. Joaquín Garrido, Peralta, Sandoval, González del Palacio (DSCC 21 de mayo de 1869, tomo IV, pág. 2150). 